\title{
La vivienda social en Madrid, 1939-1959 1
}

\author{
Jesús LóPEZ DíAz *
}

\begin{abstract}
RESUMEN
La autarquía económica, el control social y la escasez de medios técnicos y humanos marcarán la política de vivienda social en el Régimen de Franco hasta 1959, fecha del cambio de rumbo

de la Dictadura, inicio de un tímido aperturismo y liberalización. Madrid en

1939 es una ciudad desordenada, parcialmente destruida por la guerra y receptora de una masiva inmigración rural; las diferentes entidades gubernamentales promoverán, con poco éxito, diversas actuaciones en materia de vivienda social, con algunos ejemplos notables para la arquitectura española contemporánea, siempre en medio del debate de la planificación urbana de la ciudad, con las implicaciones sociales, politicas y económicas que ello conlleva.
\end{abstract}

\begin{abstract}
The economic autarky, the social control and the shortage of technicians and humans resources will mark the policy of social house in Franco's regime until 1959, date of the course change of the Dictatorship, beginning of a timid opening-up and liberalization. Madrid in 1939 is a disordered city, partially destroyed by the receiving war and receiving of a massive rural immigration; the different governmental organizations will promote, with little success, diverse performances in the matter of social house, with some remarkable examples for the contemporary Spanish architecture, always in the middle of the debate of the urban planning of the city, with the social implications, political and economic that it entails.
\end{abstract}

\footnotetext{
* Becario del Departamento de Historia del Arte, UNED. Fotografias, obra de Miguel Angel Rebollo.

Este artículo supone una síntesis de un trabajo más extenso elaborado como Trabajo de Investigación del Doctorado en Historia del Arte del autor, periodo a cargo de la Catedrática María Dolores Antigüedad del Castillo-Olivares, a la cual agradezco su revisión y orientaciones.
} 
El presente artículo es una revisión de la situación de la vivienda social en Madrid desde el final de la Guerra Civil hasta finales de los 50. Casi dos décadas que concluyen en 1959 con el Plan de Estabilidad aprobado por el Gobierno, reflejo de un giro en el rumbo del país y el inicio de un nuevo periodo político y económico, con el dominio de los tecnócratas del Opus Dei tras el fracaso del falangismo. Además en 1957, entró en funcionamiento el Plan de Urgencia Social para intentar aliviar el grave problema del chabolismo y la infravivienda en las áreas peri urbanas de Madrid. El Plan supuso una nueva forma de enfocar el problema al incorporar a la tarea al capital y a la empresa privada, hecho determinante del cambio positivo de la situación de la vivienda social (cuantitativamente), junto a la tardía creación, en 1957, del Ministerio de la Vivienda.

Madrid pretende convertirse en 1939, tras el triunfo de los militares sublevados que lidera el General Franco, en símbolo del nuevo poder. En medio de una España que se transformaba en un pais cada vez menos agrario y más urbano. La ciudad creció desmesuradamente, sin que las autoridades fueran capaces en ningún momento de controlar o dirigir este crecimiento masivo, rápido y dominado por la miseria de los nuevos inmigrantes, pobres, que abandonaban el campo para instalarse en la ciudad, acelerando un proceso comenzado décadas atrás. Se sumaban asi el problema heredado de los suburbios, al de la reconstrucción de una ciudad sitiada y bombardeada durante casi tres años. Los gobernantes vencedores tampoco olvidarán que en estos suburbios se alojó en los años de la 11 República y en los de la confrontación, una importantísima parte del movimiento obrero izquierdista y anarquista contrario al fascismo.

De fondo existió durante este periodo un importante debate sobre la construcción de la nueva ciudad, íntimamente unido a la diferente concepción del Estado entre falangistas y el resto de las familias políticas franquistas. Mientras los seguidores de José Antonio propugnaban la superación de la lucha de clases (que no su desaparición), el resto de los grupos propondría soluciones de segregación de barrios obreros, alternativas que defendieran mejor los restos de la ciudad burguesa decimonónica en claro desmoronamiento.

La vivienda obrera del siglo XIX, mínima y antihigiénica, se convirtió en un referente para la utopía constructiva, que según Benévolo ${ }^{2}$, fracasa

2 Benevolo, L.: Origenes del urbanismo moderno. Madrid, H. Blume Eds., 1979, págs. 61 y siguientes.

Según Benévolo, las utopias de Owen, Saint-Simon o Fourier, son ya criticadas en el Manifiesto del Partido Comunista de 1848, por identificar orden urbano con orden social y político; 1848 es el comienzo del urbanismo moderno y el momento de separación entre la experiencia ur- 
después de 1848, punto de inflexión y de inicio de la triunfante ciudad burguesa. La vivienda obrera es un problema político, social y urbano que en la mayoría de las ciudades europeas no se resolvió hasta la reconstrucción europea tras la II Guerra Mundial, con las salvedades de la Viena socialista o el Berlín de entreguerras.

Tras el final de la II Guerra Mundial y su posterior labor de reconstrucción, la sociedad europea inició un período de prosperidad y las clases sociales sufrieron un proceso de transformación y equilibrio. Un tipo de vivienda mínima pero digna, ya no es sólo reclamada por los obreros fabriles, sino por trabajadores de clase baja de la mayoría de los sectores productivos. Es lo que denominamos vivienda social, y que en la mayoría de las legislaciones europeas cabría calificar como vivienda protegida.

En el caso de España esta definición legal de vivienda protegida, que surgió con la Ley de 19 de abril de 1939, no sólo incluyó la vivienda social - vivienda mínima pero adecuada a familias de rentas reducidas que no pueden acceder a las viviendas de mercado- sino que se aplicó también a otros grupos laborales como militares, funcionarios de las diferentes administraciones o trabajadores de empresas públicas.

\section{METODOLOGIA Y FUENTES}

Esta investigación se ha realizado consultando los expedientes de las viviendas protegidas que se encuentran en tres diferentes archivos de la Administración: archivo de la Dirección General de la Vivienda, la Arquitectura y el Urbanismo, Secretaría de Estado de Infraestructuras, Ministerio de Fomento; Archivo Regional de la Comunidad de Madrid; y archivo del Instituto de la Vivienda de Madrid -IVIMA-, Consejería de Obras Públicas, Urbanismo y Transporte, Comunidad de Madrid.

Expedientes: incompletos, sin ordenar, mal conservados (aún cuando cuentan con material original firmado por los principales arquitectos españoles del siglo xx), con información dispersa entre los propios archivos, o que han sido remitidos a otros departamentos o instituciones, algunos ilocalizables (a causa del sistema de catalogación / archivo). No se pretendía desarrollar un catálogo exhaustivo, sino realizar una aproximación de carácter histórico ${ }^{3}$.

bana y la izquierda política, el fin de la utopía y el triunio de la técnica que en los años siguientes transformará Londres, París o Barcelona liderados por el nuevo conservadurismo europeo.

3 En la investigación se han catalogado 122 grupos de viviendas, de las cuales se citan en el presente artículo solamente los ejemplos más notables del periodo investigado. 
Otras fuentes consultadas han sido revistas de la época, de temática arquitectónica y urbana, principalmente los medios de difusión de los organismos oficiales participantes en esta labor. También se ha consultado la bibliografía más específica sobre este momento y esta cuestión, tanto de material publicado y escrito durante el periodo de estudio de este trabajo (1939-1959), como los estudios históricos de investigación actuales ${ }^{4}$.

\section{EL PERIODO DE RECONSTRUCCIÓN (1939-1951): EL FINAL DE LA GUERRA CIVIL Y EL INICIO DE LA AUTARQUIAA}

La década de 1940 supuso el período de hegemonía del nacional-sindicalismo, el modelo político que proponía Falange, inspirado en el fascismo, pero con el que no simpatizaban otros grupos franquistas como la Iglesia o los monárquicos. Durante la II Guerra Mundial, España mantuvo una supuesta neutralidad que no ocultaba las simpatías y las deudas a la Alemania nazi. Con el final de la Guerra en 1945 comienza la etapa más dura del Régimen, iniciando el camino de la supervivencia, los años más duros de aislamiento y ostracismo internacional. La presión y las críticas internacionales provocaron en el Régimen una reacción doble: hacia el exterior se esgrimió la bandera del catolicismo y el anticomunismo como señas de identidad del Régimen; hacia el interior el cambio de gobierno de 1945 relegó al sector falangista en favor de los ministros católicos.

El 12 de diciembre de 1946 la ONU dictó medidas políticas y económicas de castigo contra Franco, sólo incumplidas por unos pocos países que se convertirán en el salvavidas internacional del Régimen (como Argentina o el Vaticano).

A finales de los 40 el panorama internacional sufría los efectos del inicio de la "guerra fría". Los Estados Unidos despliegan una política internacional de alianzas contra la URSS, y en 1947 su administíación inicia contactos con el franquismo. En 1950 estalla la guerra de Corea y en China la revolución comunista, los aliados occidentales rebajan la dureza hacia el franquismo. En ese mismo año España será admitida por fin en organismos internacionales como la FAO o la UNESCO. Lo peor del ostracismo internacional ha pasado, aunque la situación de España ante la comunidad internacional no se normalizará hasta mediados de los 50 .

\footnotetext{
4 Las dos obras actuales más importantes son: MOYA GONZALEZ, L.: Barrios de Promoción Oficial. Madrid 1939-1976, Madrid, COAM, 1983; SAMBricio et al.: La vivienda en Madrid en la década de los años 50: el Plan de Urgencia Social, Madrid, Ayuntamiento de Madrid y Ministerio de Fomento, 1999.
} 


\section{La autarquía económica y su repercusión social}

La guerra arruinó el importante crecimiento económico del primer tercio de siglo, un crecimiento desequilibrado que no había conseguido sacar a España del retraso que le separaba de la Europa industrial.

Los principales efectos de la Guerra Civil sobre la economía española se cristalizaron en la caída de la producción agraria e industrial a niveles prebélicos; en daños en infraestructuras, no así en pérdidas en maquinaria $e$ instalaciones que no pueden considerarse catastróficas; y en la destrucción de 250.000 viviendas, mas un número similar dañadas (el $10 \%$ de las viviendas españolas), cifra en absoluto comparable a la devastación que sufrieron los países europeos más afectados por la II Guerra Mundial.

"No fueron, pues, los destrozos físicos de la guerra, ni en la industria ni en el campo, los que condicionaron de un modo más grave la evolución de la economía española (...) la peor consecuencia económica de la Guerra Civil fue la de los años subsiguientes, cuando el franquismo desenganchó a España durante un tiempo de las aceleradas líneas de progreso económico seguidas por los otros paises europeos occidentales apenas concluida la Guerra Mundial» ${ }^{5}$.

Como señalan Barciela et al. al examinar globalmente la trayectoria de la política económica franquista, su signo más sobresaliente fue «la resistencia a cambiar, la fuerza de la inercia, siempre el poder a remolque de los acontecimientos. No puede ensalzarse, precisamente, la capacidad de reacción de un régimen que tardó dos décadas en reconocer que su sistema no funcionaba y en convencerse de que la salida de la crisis radicaba en la liberalización que tanto había criticado" 6 .

El sistema autárquico intervencionista y nacionalista de la década de los cuarenta supuso un freno al desarrollo económico y se convirtió en el periodo de mayor recesión económica de nuestra Historia, multiplicando los efectos producidos por los desastres de la guerra. Efectos menores que en la mayoría de los paises europeos que, sin embrago, produjeron en nuestro país una recuperación mucho más lenta.

"La autarquía fue una decisión tomada libremente por razones ideológicas"; el deseo de autosuficiencia del Régimen, tenía como único objeti-

\footnotetext{
5 Garcia Delgado, J.L. y Jiménez, J.C.: Un siglo de España. La economia. Madrid, Barcelona, Marciai Pons, 1999, pág. 108.

6 Barciela, C. et al.: La España de Franco (1939-1975). Economía. Madrid, Síntesis, 2001, págs. 9-13.
} 
vo el aislamiento internacional de la sociedad española. Retomando, ahora sin oposición, el nacionalismo económico español de la primera mitad de siglo, desarrollando el paternalismo tradicional en todas las esferas de la vida de los ciudadanos ${ }^{7}$.

El eje de esta política burocrática, hiper-regulada y sin capital extranjero, fue el instituto Nacional de Industria (INI), creado en septiembre de 1941. La política del INI en los años 40 fue un fracaso por la lentitud y mala gestión de proyectos y recursos.

Estos efectos económicos fueron sufridos por una población española que ascendía a 25,87 millones de habitantes. Como consecuencia de la guerra la población activa se agrarizó en la década de 1940, sin embargo, este incremento de la mano de obra no conllevó un aumento en la producción, se mantenía el proceso de urbanización y el éxodo rural de una sociedad que en 1930 había dejado de ser predominantemente agraria. En los años 40 son cerca de 800.000 campesinos y jornaleros los que abandonan el campo, población agraria sin cualificación que aumentó la masa obrera de las ciudades.

\section{La "ciudad del movimiento"}

«... Madrid, abominable de masas en chancletas! Posaderas de oficina sentándose en sillones imperiales. iY al fin el Escorial, El Escoriall Origen y sueño del Madrid cesáreo. Sus tumbas profanadas por los gusanos rojos..." ${ }^{8}$.

En febrero de 1938 se celebró en Burgos, sede del Mando Militar del Ejército sublevado, una reunión con más de doscientos arquitectos liderados por Pedro Muguruza. Las únicas palabras publicadas que nos han llegado son las del discurso de clausura del encuentro que pronunció el líder falangista Raimundo Fernández Cuesta que enuncia la ciudad ideal que sueña el falangismo, «la ciudad del Movimiento»:

«... no construir barriadas obreras aisladas que no es otra cosa que lievar la diferenciación de clases a la arquitectura, construyendo edificios que pa-

BARCIELA et al recoge la opinión de la mayoria de estudios económicos que califican la autarquía como "empresa descabellada sin fundamento económico racional», frente a los que defienden la política económica franquista como salida a la reconstrucción y al aislamiento internacional. Op. cit., págs. 29-38.

" Palabras de Enrique Giménez Caballero. Citado en DiAz NOsTY, B.: “Madrid imperial", en AA.VV.: Madrid: cuarenta años de desarrollo urbano (1940-1980). Ayuntamiento de Madrid, 1981. 


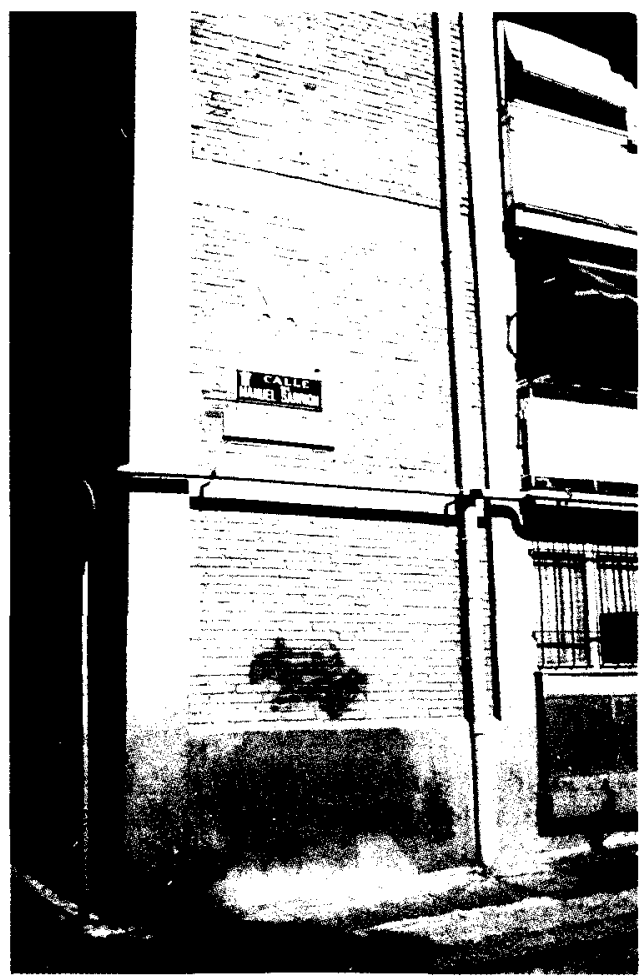

El simbolo de falange en un edificio.

recen tener la finalidad de hacer resaltar la diferencia de los seres que en ella habitan respecto de los demás. Cuando el ideal sería que en los distintos pisos de una misma casa pudieran habitar, indistintamente, personas de distinto rango social» ${ }^{9}$.

Falange intentaba liderar el proceso de reconstrucción y plasmar en la nueva arquitectura y urbanismo los ideales expresados en su programa político ${ }^{10}$. Estas ideas quedan plasmadas en el documento ldeas generales

9 El discurso (14 de febrero de 1938) citado en DIÉGuEZ, S.: Un nuevo orden urbano: «EI Gran Madrid" (1939-1951). Madrid, Ministerio de Administraciones Públicas y Ayuntamiento de Madrid, 1991, págs. 5 y 6.

10 Los llamados 26 puntos de Falange: «11. El Estado nacional-sindicalista no se inhibirá cruelmente de las luchas económicas entre los hombres, ni asistirá impasible a la dominación de la clase más débil por la más fuerte. Nuestro régimen hará radicalmente imposible la lucha de clases, por cuanto todos los que cooperan a la producción constituyen en él una totalidad orgánica." 
sobre el Plan Nacional de Ordenación y Reconstrucción, elaboradas por los Servicios Técnicos de FET y de las JONS (1939).

La visión falangista del barrio urbano ideal se basa en la desaparición de las barreras clasistas y en la familia como forma "superior al individuo". "Como arquitectos podemos hacer notar que hasta ahora se construyen barrios independientes y distintos para diversas clases sociales, que fomentan y excitan la lucha de clases. $Y$ ahora queremos hacer barrios para gentes que estén unidas por un fin común, dentro de estos barrios estará comprendida toda la jerarquía desde la máxima hasta la mínima" "1. No se cuestiona la separación y la superioridad jerárquica entre clases, se cree que los problemas que conlleva esta diferenciación de la ciudad tradicional, se superarían, y se evitaría así llegar a situaciones de tensión en las que estos barrios favorecen las opciones radicales obreras: la «zonificación urbana es la tradición material de la lucha de clases socialista que hay que desterrar".

En este documento Falange también cita la necesidad de diseñar un Plan de Vivienda, regido por la separación en habitaciones del matrimonio y de los hijos por sexos; dotando a la vivienda de una pieza que "simbolice la idea del hogar »; y con unos mínimos higiénicos (ventilación, orientación, iluminación, agua) conforme a las diferentes características regionales.

\section{La Junta de Reconstrucción}

A finales de 1938, se creó en Burgos la Dirección General de Regiones Devastadas y Reparaciones (DGRDR), pasando a formar parte de la estructura del Ministerio de Gobernación, y cuya dirección se encargó a Moreno Torres. Regiones Devastadas dictaminaba que las poblaciones con destrucciones superiores al $75 \%$ fueron nominadas como "adoptadas" por Franco (en total 102 pueblos en toda España, incluyendo algunos barrios de Madrid que habian sido primera línea del frente de guerra).

Al año siguiente se crea la Dirección General de Arquitectura (DGA), que dirige Pedro Muguruza sin abandonar su puesto al frente de los Servicios Técnicos de Falange. Esta Dirección General, junto a la de Regiones Devastadas, se adscribe al Ministerio de Gobernación. Sin embargo, el recién creado Instituto Nacional de la Vivienda (INV), dirigido por Fede-

11 Ideas generales sobre el Plan Nacional de Ordenación y Reconstrucción. Servicios Técnicos de FET y de las JONS. Madrid, Año de la Victoria [1939]. 
rico Mayo, y que había sido constituido por ley de 19 de abril de 1939, se encuadra en el Ministerio de Trabajo.

Estas instituciones son las encargadas de dirigir la reconstrucción de Madrid. Para organizar esta tarea y armonizar la actuación de todos los organismos se creó la Junta de Reconstrucción de Madrid (JRM) por Orden de 7 de octubre de 1939, formada por una Comisión Interministerial. La Junta mantuvo dos grandes líneas de trabajo: la reconstrucción material de la ciudad y la redacción del nuevo Plan General de Ordenación Urbana de Madrid, obra de Pedro Bidagor, cuyo proyecto elaborado en 1941 verá la luz con retraso, al publicarse por Ley el 1 de marzo de 1946. Esta es la fecha definitiva de la aprobación del Plan General de Urbanización de Madrid y Alrededores (pues afectaba no sólo a la capital sino a los 28 términos municipales limítrofes, muchos de los cuales serían anexionados por Madrid entre 1948 y 1954). Esta Ley también disponía la creación de la Comisaría General para la Ordenación Urbana de Madrid y sus Alrededores (COUMA), a la que pasaba a formar parte la Junta de Reconstrucción.

El Plan sufrió un retraso fruto de la tirantez de la situación política. El propio alcalde de Madrid, Alberto Alcocer, habia presentado públicamente otra propuesta de Plan de Ordenación de Madrid, obra del ingeniero municipal José Paz Maroto.

Bidagor, en teoría, continuó la idea de la superación clasista falangista. En la práctica, el diseño que propuso, y que sin reconocerlo continuaba las ideas expuestas por el proyecto Zuazo-Jansen de 1929, disgregaba el Ensanche burgués del extrarradio obrero a través de anillos verdes de separación. Anillos que también circundan las propuestas de barrios suburbiales y ciudades satélites en el entorno de Madrid, y que evitarían el crecimiento en mancha de aceite de las últimas décadas, apostando por la zonificación.

Se definen también en el Plan de Bidagor los poblados satélites, de nueva planta o aprovechando pequeñas poblaciones limítrofes. Son núcleos autónomos que absorberían el futuro crecimiento de la ciudad, y que estarían comunicados a ella y entre si por vías de tráfico y circulación. Se clasificaron en 3 grupos dependiendo de su función: poblados de servicio de zonas industriales y militares; poblados de albergue de población obrera que trabaje en Madrid pero sin recursos para vivir en la ciudad; y poblados de vivienda con menor densidad y más naturaleza (ciudades jardín residenciales). Esta distribución clasista de los poblados satélites es contraria a las formulaciones falangistas, por lo que Muguruza no dudó en criticarlo, para él debía superarse la división social.

El Plan, en lo que se refiere al tema de la tipología edificatoria, proponía sustituir la manzana cerrada tradicional por el bloque abierto de doble 
crujía, en medio de espacios verdes unificados por vías, frente al aprovechamiento máximo de la manzana y del solar, lo que podría provocar el retraimiento de los constructores. Así que en el Plan todo queda en un enunciado amplio y genérico de tipologías edificatorias.

\section{El debate sobre la segregación de los barrios obreros}

Durante los primeros años de 1940 proliferan un número importante de foros de debate sobre el tema de la ciudad, el diseño urbano y la vivienda. Quizás, el momento para nuevos planteamientos era dramáticamente oportuno, por las posibilidades que ofrecía reconstruir tantas zonas asoladas. Sin embargo, el enfrentamiento entre las dos concepciones políticas imperantes se trasladará también al campo del urbanismo y la vivienda.

Un duro ejemplo de la visión más conservadora, lo encontramos en la conferencia del concejal del Ayuntamiento de Madrid, José M. ${ }^{a}$ Díaz-Soler, pronunciada en 1957 en el Círculo de la Unión Mercantil:

"El Madrid actual, extramuros de aquellos pegotes de sus ensanches, crece armonioso y arrollador. Pero tengamos cuidado; es preciso poner ya limites a ese crecimiento, porque no podemos hacer de Madrid, no debemos hacer de nuestra capital un monstruo. (...) De aquí que sea imperiosa la política consistente en dejar a Madrid quieto ya, no extenderlo más, no industrializarlo más; no hacerlo más incómodo ni más obrerista ni más suburbano. Si, en cambio, confortable hacia dentro, más sano y alegre en su interior, más necesitado de reforma interior que de expansión. $Y$ en cambio, tonifiquemos la provincia, hagamos cómoda y alegre la vida del obrero en la provincia (...) ... retornar a su origen a los que vinieron sin causa ni medios económicos de subsistencia,... limitando, digámoslo claro, no la libertad de los españoles, sino la licencia o libertinaje que consiste no en el limpio ejercicı a fijar su residencia en el punto que deseen sino en el éxodo gregario, a veces impuro, a veces angustiado por la necesidad del campo a la metrópoli, de la provincia pobre a la gran urbe...» ${ }^{12}$.

En el polo opuesto se encuentra el criterio de Muguruza, quien no recorta críticas a la actuación especulativa de la burguesia en etapas anteriores, a la que acusa de haber hecho negocio de la vivienda humilde. La solución que propone es la de crear poblados, pero poblados donde se mezclen las clases sociales para evitar barrios obreros, "preferible lograr

12 Soler Diaz-Guijarro, J.M.: «Problemas de Madrid a la luz de mi experiencia en el Ayuntamiento", citado en Garcia Martin, A : Froceso de anexión de los municipios limitrofes a Madrid. Ayuntamiento de Madrid, 1991, pág. 79. 
el ideal de una jerarquización absoluta en el conjunto del poblado, con un carácter de hermandad, de gran familia social; ligada incluso al patronazgo de quien incorpora con su rango social un matiz de tradición española al conjunto nuevo ${ }^{13}$. El orden constructivo ideal es el tradicionalismo arquitectónico que aprovecha los materiales locales y la economía de medios: ya en esta fecha de 1940 anticipa la idea de la bóveda "catalana» (que propagará más tarde Luis Moya, y que utilizarán Cabrero o Zuazo), o el articulado de cerámica palentino, los sistemas de bóveda exterior,...; incluso sugiere, como medida de emergencia, recuperar las cuevas tradicionales mejorándolas al máximo.

La disyuntiva entre proyecto y realidad, irá modificando las propuestas y las opiniones del entorno falangista. Luis Pérez Mínguez, arquitecto simpatizante, publica en el diario Arriba en 1943 (el periódico falangista), un artículo donde expresa la «imposibilidad económica de estas gentes», pero a la vez ve "un caldo de cultivo peligroso". Su propuesta se basa en acabar con la división entre ciudad y suburbio desarrollando el estudio de la ciudad entera, como una agrupación y con un ideal común ${ }^{14}$.

La otra corriente, de talante conservador y continuista con los ideales políticos prerrepublicanos, tiene su órgano de expresión en los Congresos de la Federación de Urbanismo y de la Vivienda, promovidos por César Cort, arquitecto y concejal del Ayuntamiento de Madrid. A diferencia de los falangistas, que culpabilizaban a la gestión municipal y a la especulación capitalista, la línea de Cort será la contraria, culpabilizar a la clase obrera y defender al propietario capitalista: "Una de las grandes fallas de la edificación presente se encuentra en la torpeza de la mano de obra y en su falta de rendimiento". Su solución: "Hay un procedimiento sencillo de lograr inmediatamente una reducción considerable en el coste de la unidad de obra, aumentar la jornada de trabajo sin variar el jornal. Y con el tiempo reducir también el jornal». Cort pide a los Ayuntamientos abaratar los solares; construir barrios enteros para economizar; estudiar la industria de la edificación, y aumentar el valor de los alquileres para que la edificación atraiga al capital ${ }^{15}$.

13 Muguruza, P.: “Conferencia sobre problemas técnicos planteados en el mejoramiento de la vivienda humilde", ponencia presentada al XV Congreso de la Asociación para el Progreso de las Ciencias, Zaragoza, diciembre de 1940. Publicado por la propia Asociación, Madrid, 1941. En esta conferencia Muguruza aporta una idea curiosa: la célula básica de organización debía ser la escuela, a tantos niños tantas familias, y tantas viviendas (de 200 a 500 casas con capacidad para 800 a 5.000 habitantes)

14 Citado por Diéguez, S.: Op. cit., pág. 149.

15 I Congreso Federación de Urbanismo y la Vivienda. Madrid, Ediciones de la Federación, 1941, pág. 199. 
La solución final se expresó en la aprobación de la Ley de Ordenación Urbana de Madrid (obra de Bidagor) y en la que todos los organismos ejercieron algún tipo de presión. Como señala Terán, el Plan proyecta una visión novedosa por la escala, aunque el sistema de anillos verdes para la ciudad y para los núcleos satélites buscaba una segregación radical de la clase trabajadora, mantenida a distancia en un entorno semirural ${ }^{16}$. O como escribió el ingeniero Martínez de Lamadrid, colaborador de Bidagor: "La distribución de las zonas industriales, además de responder a los criterios normales de zonificación conocidos (...) ha obedecido fundamentalmente a la necesidad de localizar las masas obreras en sectores de la ciudad, y en núcleos satélites de población con vida material autónoma, en fácil contacto con su comarca rural. De esta forma las zonas industriales constituyen verdaderos baluartes defensivos contra la invasión de masas de población inactivas que se sitúan en los alrededores, constituyendo los cinturones suburbanos de miseria contra la que se lucha dificilmente" 1 . Como quiera que a finales de los 40 los anillos verdes son ambicionados por especuladores y por las instituciones como única salida para obtener un suelo más económico, las ideas de Bidagor y todo el debate entre $\mathrm{Mu}$ guruza y Falange frente a los sectores conservadores, quedó superado por la realidad.

\section{La labor de Regiones Devastadas}

Los barrios "adoptados" de Madrid, donde trabajó Regiones Devastadas, comprendian la margen derecha del río Manzanares (Ctra. de Extremadura, Puente de Toledo, Usera, Estación del Norte y Entrevías), más los entonces pueblos limitrofes de Carabanchel Bajo y Villaverde. Regiones Devastadas, al igual que otros organismos, utilizó a presos franquistas en su labor bajo el sistema de redención de penas por el trabajo. Las dos líneas de actuación se centraron en la redacción de Planes de Ordenación de los barrios adoptados, y en reparaciones en bloques de viviendas semidestruidas y erigir albergues para alojar familias mientras se construian viviendas de nueva planta. Regiones Devastadas tendrá actuaciones de nueva planta muy importantes en este momento, porque erigirá algunos bloques según los parámetros falangistas de cohabitación de clases sociales, bajo las directrices de la moral católica. El primero y ejemplo de sus

16 Terán, F. de: “Notas para la historia del planeamiento de Madrid. De los orígenes a la Ley Especial de 1946", págs. 22-25. Ciudad y Territorio, n. 2/3, 1976, Madrid.

lbidem, pág. 25. 


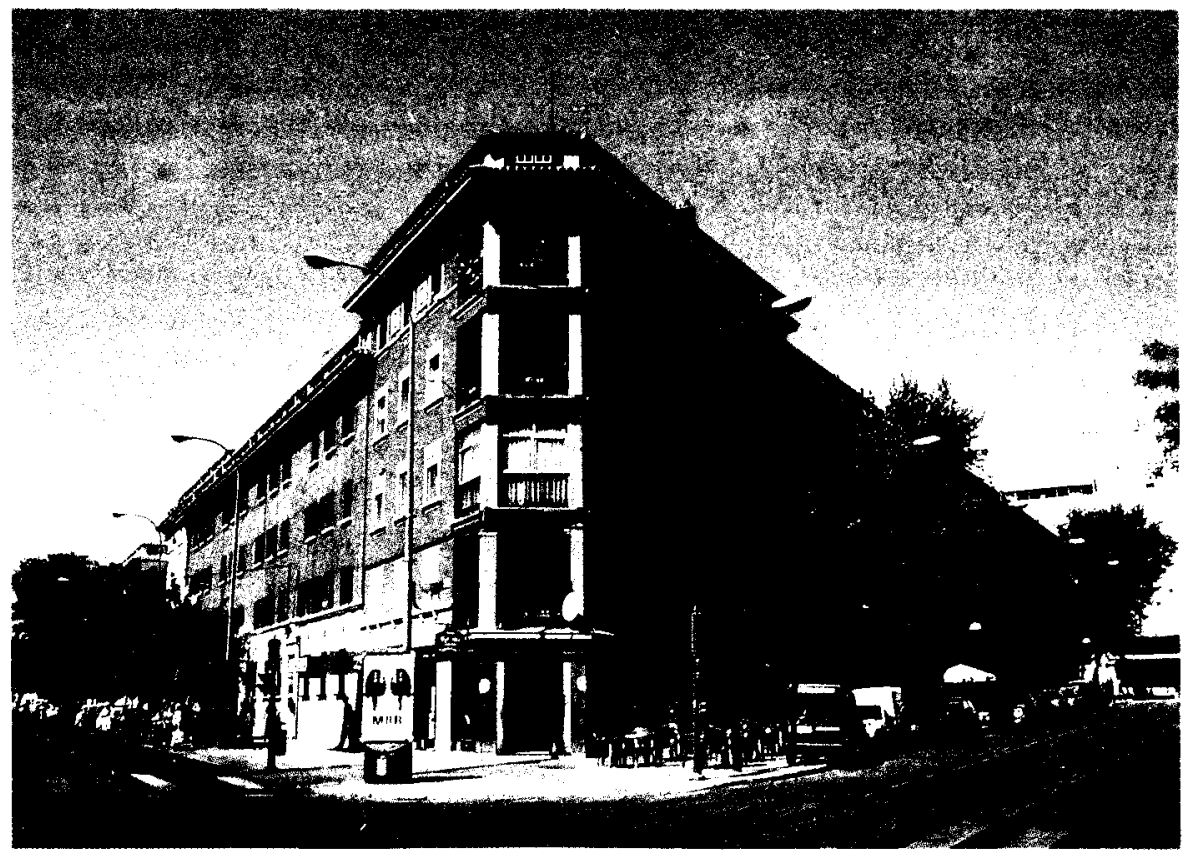

Viviendas de renta reducida en Carabanchel Bajo.

ideal constructivo se erigió en Carabanchel Bajo, luego siguieron actuaciones en Marqués de Vadillo en Madrid.

Viviendas de renta reducida en Carabanchel Bajo

Situación: General Ricardos, 220 / Av. Plaza Toros Vista Alegre.

Arquitecto: Luis Garcia de la Rasilla (proyecto de 1940).

El diseño se basa en el proyecto de E. Amann para el concurso de Bilbao de 1932. Se preconiza la solución en escalera frente a la galería-corredor (sistema de distribución de inspiración «rusa», y que, según el autor, Le Corbusier ya considera fracasado). Se reconoce la importancia de la orientación con las zonas vivideras al sol y las húmedas al norte. El conjunto lo forman 3 bloques de planta abierta en una manzana triangular, con jardín interior. Se diseñan 3 tipos diferentes de viviendas teniendo en cuenta "las diferentes necesidades": "Como es natural, ni remotamente hemos pensado en adoptar soluciones marxistas a base de proyectar salas de estar convertibles de noche en dormitorios, tan anticristiano por su falta de moral y lo poco familiar. La vivienda ha de responder a las necesidades de un hogar cristiano (...) No 
hay salud ni moralidad posibles donde se hacinan seres humanos de todas las edades $y$ todos los sexos en repugnante promiscuidad" 18 .

\section{Muguruza y la Dirección General de Arquitectura}

La Dirección General de Arquitectura presentó el proyecto del primer poblado del franquismo, el Cerro de Palomeras, que en realidad pertenecía al primer proyecto de poblados satélites, desarrollando así las propuestas del Plan de Bidagor.

\section{Cerro de Palomeras}

Situación: Cerro Palomeras (Arroyo del Olivar, Av. Palomeras y Av. Albufera).

Arquitectos: Ramiro Avendaño y Paisán y Luis Diaz-Guerra y Milla.

Anteproyecto de agosto de 1939 inspirado por Muguruza y desarrollado por los Servicios Técnicos de Falange. Lo aprueba la JRM en 1940 y la DGA lo presenta en la exposición de sus trabajos en 1942. Con capacidad para 15.000 habitantes distribuidos en 5 núcleos de 660 viviendas, cada núcleo incluia servicios administrativos y religiosos. El $75 \%$ de las viviendas serían unifamiliares de 1 ó 2 plantas, de carácter semirural (corral y patio) y máxima economia de construcción.

Aunque Cerro Palomeras no se construye, es el modelo que inspira las actuaciones posteriores en el poblado Tercio y Terol o en La Ventilla. Articulados ambos en torno a una plaza con iglesia (y abrevadero), las dependencias de la administración, y a su alrededor las viviendas de 1 ó 2 alturas (y algún pequeño grupo de 3 plantas); todas con patio y corral, según diseños diferentes dependiendo del número de habitaciones y oscilando su superficie entre los 50 y $100 \mathrm{~m}^{2}$ (viviendas mínimas de carácter semirural).

\section{La actividad del Ayuntamiento de Madrid}

El Ayuntamiento se habia convertido en los decenios anteriores en una institución sin recursos reales y heredera de una estructura deficiente. La

18 Reconstrucción, n. ${ }^{\circ} 26,1942$, págs. 353-362. En 1946 se insiste en la importancia moral del diseño de las viviendas según las clases para "conseguir una verdadera hermandad cristiana 
Guerra multiplicó este problema, al que se añadirá la emigración rural producto de la política autárquica.

Los intentos que durante las últimas décadas había realizado el Ayuntamiento de diseñar un Plan de Ordenación propio se le escaparon definitivamente de las manos con la aprobación definitiva del Plan de Bidagor de 1946. Esta situación resultó incómoda para muchos funcionarios municipales de talante conservador, como el arquitecto César Cort o el ingeniero José Paz Maroto, y para el entonces alcalde de Madrid, Alberto Alcocer. Paz Maroto, en 1943, se queja desde el Ayuntamiento de las "recortadas competencias de la corporación que lo máximo que puede pretender es elaborar propuestas que debe elevar a la superioridad" ${ }^{19}$. El Ayuntamiento estaba interesado en la incorporación de los municipios limítrofes, pero el espacio territorial que le asignaba la Ley de Bases de 1944 le parecia excesivo y con un costo de urbanización inasequible.

En 1944 se crea el Patronato Municipal de la Vivienda (PMV), dedicado a construir viviendas para los funcionarios del Ayuntamiento aprovechando los recursos legales y financieros de la ley de viviendas protegidas (dictada por el INV el 19 de abril de 1939). El foco de actuación del PMV en los años 40 fue principalmente la Ctra. de Extremadura, donde colaboró con Regiones Devastadas.

Un ejemplo de las actuaciones municipales del PMV lo encontramos en la Colonia Molino de Viento. La Colonia Los Olivos, las nuevas viviendas de la Colonia Moscardó, Cerro Bermejo y en la segunda mitad de los 40, la Colonia Girón, son actuaciones similares.

\section{Molino de Viento (Puerta del Ángel / P. ${ }^{\circ}$ de Extremadura)}

Pequeña actuación de vivienda para funcionarios y empleados del Ayuntamiento con plantas mínimas de $32 \mathrm{~m}^{2}$, en edificios de 2, 3 y 4 plantas con galería corrida en fachada a modo de corrala de aspecto semirural, o unifamiliares en hilera de 1 planta, que algún autor ha calificado como "chabolismo institucionalizado" 20 .

entre las diferentes clases, que necesariamente han de existir. Los más acomodados, con mayor influencia social, pueden hacer como de hermanos mayores de aquellos en inferiores condiciones, y juntos, guiados por el mismo ideal, servir mejor a Dios y a España". Ibidem, n. 62, 1946, págs. 131-136.

19 Garcia Martin, A.: Op. cit., pag. 62

20 Moya Glez., L.: Barrios de Promoción Oficial. Madrid 1939-1976, Madrid, COAM, 1983, pág. 236. 


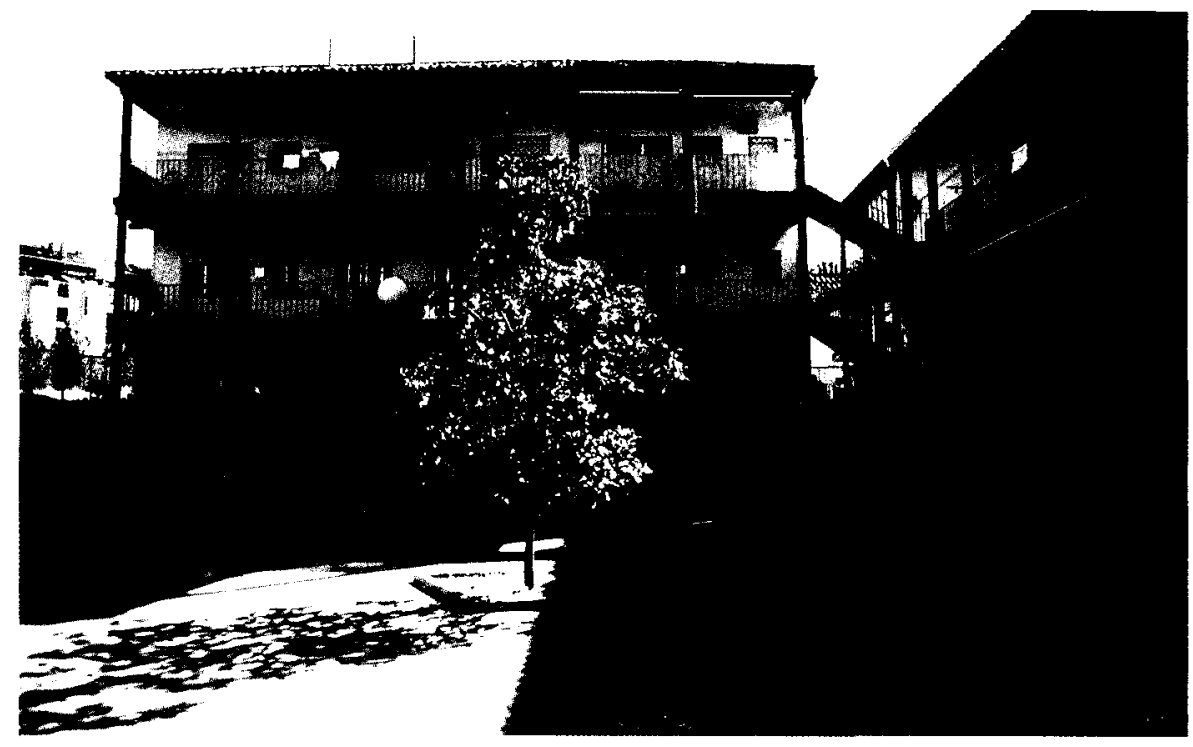

Molino de Viento (Puerta del Ángel / $P{ }^{\circ}$ de Extremadura).

El caso del proyecto de Nuestra Señora de las Victorias (c/General

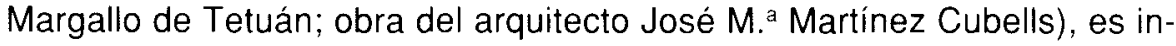
teresante por ser proyectado en 1943 por el entonces Ayuntamiento de Chamartín de la Rosa (viviendas para obreros de la construcción con patio interior de manzana y superficies en planta entre los 75 y $125 \mathrm{~m}^{2}$ ). En la memoria del proyecto encontramos de nuevo una formulación apelando a la «moralidad» necesaria a la hora de diseñar estas viviendas obreras: "Con estos tipos de vivienda que evitan la inmoralidad que supone la promiscuidad de sexos en las familias, así como por superficie evitan el pretexto para posibles maltusianismos totalmente anticristianos, y que, los católicos, hemos de combatir sin tregua ni descanso" 21 .

Otro ejemplo interesante lo constituyen las viviendas para empleados de la Empresa Municipal de Transportes en San Cristóbal de Fuencarral ( $\mathrm{P} .{ }^{\circ}$ de la Castellana, 292-300), obra del arquitecto Secundino Zuazo (postergado por el decreto de castigo a los arquitectos "desafectos"). Al igual que Luis Moya y Francisco Cabrero, recurre a la bóveda tabicada y al ladrillo para levantar uno de los mejores ejemplos de vivienda de los 40 .

21 Archivo Dirección General Arquitectura, Vivienda y Urbanismo, expediente M-935-VP. 
En 1944 Bidagor continúa lamentándose de la falta de solares en la ciudad, "se están a punto de terminar» afirma, producto del alto valor del suelo por la especulación amparada, a su juicio, en el Estatuto Municipal. La respuesta municipal no se hace esperar, y en el mismo ciclo de conferencias en el que actuaba Bidagor, un representante del Ayuntamiento afirma la necesidad de acometer las anexiones de la capital con la máxima urgencia. Para el Ayuntamiento los términos más necesarios de anexionar serían Chamartín (absorbida ya físicamente, y donde se proyectaba la Av. del Generalísimo); Canillejas, Villaverde y Carabanchel Bajo, los términos donde pretendía asentarse la industria, de cuyo potencial el Ayuntamiento no parecía ser ajeno. De todos modos, el texto vuelve a demostrar los temores municipales a las anexiones que se planean desde la Comisaría ${ }^{22}$.

El Gobierno retira de la alcaldía de Madrid al conservador Alberto Alcocer y nombra al Director General de Regiones Devastadas, José Moreno Torres, bajo cuyo mandato se realizó todo el proceso de anexiones (1948-1954). De esta forma Madrid multiplicó su superficie por diez, e incrementó su población en 350.000 habitantes. Con estas anexiones se conseguirá por fin disponer de una importante cantidad de metros cuadrados de suelo a un precio mucho menor que el del término de Madrid, convirtiéndose en el área de actuación "favorita» de la OSH y el INV en la década de los 50.

\section{La labor del Instituto Nacional de la Vivienda (INV)}

El 19 de abril de 1939 se crea el Instituto Nacional de la Vivienda dependiente del Ministerio de Trabajo. Su dirección recae en Federico Mayo. La misma ley de abril de 1939 crea la figura de "vivienda protegida", instrumento legal que ampara la construcción de la vivienda «mínima». Aunque también servirá para gestionar ayudas a colectivos protegidos por el estado (militares, funcionarios,....).

Según dicha ley, el INV es el organismo capacitado para aprobar ios proyectos de construcción de "vivienda protegida" y para dictar todo lo referente a normas de edificación, inspección, sanción, alquiler, financiación,... y dictar qué organismos de la administración o del movimiento sindical pueden acogerse y cómo han de financiarse las viviendas protegidas.

22 BIDAgOR, P.: “La organización de Madrid. Estructura urbana. Zonificación», págs. 31-51; GASCON y MARIN: "Aspectos legales de la transformación", págs. 118-125; en El Futuro Madrid, Publicaciones del Instituto de Estudios de la Administración Local, Madrid, 1945. 
Quizás la función principal del INV consistía en diseñar un plan de vivienda protegida para todo el Estado: el Plan Nacional de Vivienda 1944-1954. Se estimaban necesarias para este decenio cerca de 1.400 .000 viviendas (incluidas las viviendas a reparar y las de nueva planta), de las que el INV podría proteger el $25 \%$. Los resultados finales no llegaron a la mitad de lo planificado.

EI INV convocó el Concurso para Viviendas Rurales, según Sambricio «aquel Concurso,..., repercutió en la arquitectura urbana al entenderse que determinados núcleos satélites debían mantener el esquema del núcleo agrícola» ${ }^{23}$, los primeros proyectos de la DGA de Tercio y Terol de 1940/1941 y algunos modelos de albergues de la DGA o de Falange caminaban en paralelo con estas mismas ideas en los mismos momentos.

Esta experiencia del Concurso abrirá las puertas al INV al camino de la experimentación y la investigación, y en la década siguiente convocará el famoso concurso de vivienda experimental con la creación de un nuevo barrio a través de los sistemas premiados. Al INV también le correspondia reordenar y regular el mercado de la construcción, por lo que dedicó parte de su esfuerzo a dictar normas de homologación, estandarización y reglamentación de todo tipo de materiales de construcción.

Las realizaciones más importantes del INV en los años 40 fueron la Barriada de San Fermín (obra de los arquitectos José Fonseca y José Gómez de Mesa) en la antigua colonia de Casas Baratas Alfonso XIII. Fonseca y Gómez Mesa modificaron la estructura en planta de las viviendas y formularon una de las primeras propuestas de planta mínima (38 $\mathrm{m}^{2}$ ) en unifamiliares adosados de una o dos plantas ${ }^{24}$.

Otra función del INV consistió en realizar proyectos y diseños para instituciones que tenían el derecho legal de construir viviendas protegidas, especialmente los Patronatos, y que por su pequeña estructura no estaban ni dotadas ni capacitadas para ello. Para el Patronato de Casas de la Armada se erigió la Colonia la Marina (c/Arturo Soria; arquitectos: José Fonseca, Gómez de Mesa, Rodríguez Cano y Ruiz de Prada), proyecto del año 1946 de los arquitectos del INV. Las viviendas protegidas de estos grupos, no sólo incluyen las sencillas de suboficiales, sino también, las de oficiales, jefes y almirantes con plantas de $150 \mathrm{~m}^{2}$ incluyendo despacho, 4 dormitorios y zona de servicio, con las mismas ayudas que establece el

\footnotetext{
23 Sambricio, C.: "La vivienda en Madrid, de 1939 al Plan de Vivienda Social, en 1959", pág 17; en La vivienda en Madrid en la década de los años 50: el Plan de Urgencia Social, Catálogo de la exposición, Ayuntamiento de Madrid, Ministerio de Fomento, 1999.

${ }_{24}$ Según Sambricio asumen «un carácter agrícola novedoso y original». Ibidem, pág. 17
} 
- IBariada Obrea. Euato fientia

tare y

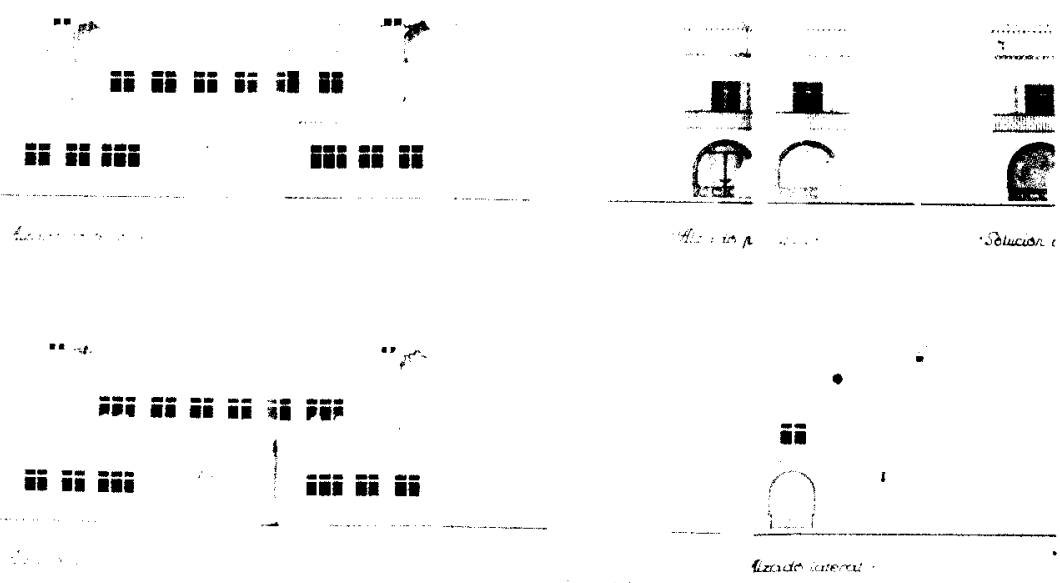

Maestranza de Cuatro Vientos / Ministerio del Aire.

INV para las viviendas protegidas en cuanto a bonificaciones, fiscalidad y anticipos a bajo interés.

\section{Maestranza de Cuatro Vientos / Ministerio del Aire}

Arquitecto: Alfredo Vegas Pérez.

Proyecto no ejecutado como vivienda protegida por los reparos del INV a los sucesivos proyectos del Ministerio del Aire, carentes en servicios colectivos, por su "monotonía", y por lo mínimo de las viviendas. Su interés radica en la fecha de la propuesta, octubre de 1939. El poblado refleja el aire ruralizante que predomina en estas construcciones agrupadas de los 40 , sea quien sea la entidad promotora.

De los Servicios Técnicos de Falange a la Obra Sindical del Hogar $(\mathrm{OSH})$

Falange fue el organismo franquista más activo y dedicado a las necesidades sociales en el bando nacional. La década de los 40 supuso el mo- 
mento de máximo esplendor político del falangismo. Muguruza compatibilizó en un primer momento sus cargos en Falange y en la DGA, lo mismo que Federico Mayo, director del INV y en los primeros años también de la Obra Sindical del Hogar y la Arquitectura (OSH).

La misión de la OSH consistía en proporcionar vivienda a los "productores" en colaboración con el INV. El productor aportaba en el momento de apuntarse el $10 \%$ del valor de la vivienda, el $90 \%$ restante lo anticipaba el INV y lo devolvía el ya dueño de la vivienda en mensualidades durante 40 años.

Falange aglutinó a algunos jóvenes intelectuales desde su fundación en 1933 (como el arquitecto José Manuel Aizpurúa, fusilado durante la guerra y autor de una de las primeras obras del racionalismo español, el Real Club Náutico de San Sebastián). Los Servicios Técnicos y posteriormente la OSH contaron con algunos de los mejores jóvenes arquitectos de la posguerra: Francisco Cabrero, Rafael de Aburto o Coderch, y Vázquez de Castro e Íñiguez de Onzoño en los 50 . Su estilo arquitectónico se relacionaba con la línea racionalista anterior (propuesta por Le Corbusier y los CIAM, y en España por el GATEPAC). Su arquitectura se convirtió en el contrapunto al "estilo imperial" interpretando en clave moderna la historia arquitectónica española, la realidad existente y su influencia a través de materiales, y contactando formalmente con la arquitectura exterior.

Virgen del Pilar

Arquitectos: Francisco Cabrero y R. Abaurre.

Superposición del modelo dúplex, construido con bóvedas tabicadas ${ }^{25}$. Altas cotas de calidad técnica y arquitectónica, mezclando artesanía, tradición y diseño (guiño a la tradición artesana en un momento álgido del período autárquico, alejándose de las soluciones estandarizadas basadas en la industria). Se convierte en un diseño aislado que no repetirá más la OSH.

La OSH erigió tres grupos en Villaverde, la zona industrial en alza gracias al tren, y que en el Plan de 1941 aparece como zona industrial (como explica Martínez de la Madrid en su conferencia sobre "El problema industrial en la ordenación de Madrid", donde apunta la necesidad de construir poblados para obreros en las proximidades de las fábricas). El terre-

25 Como las diseñadas por Luis Moya en Usera como vivienda experimental para la DGA. 


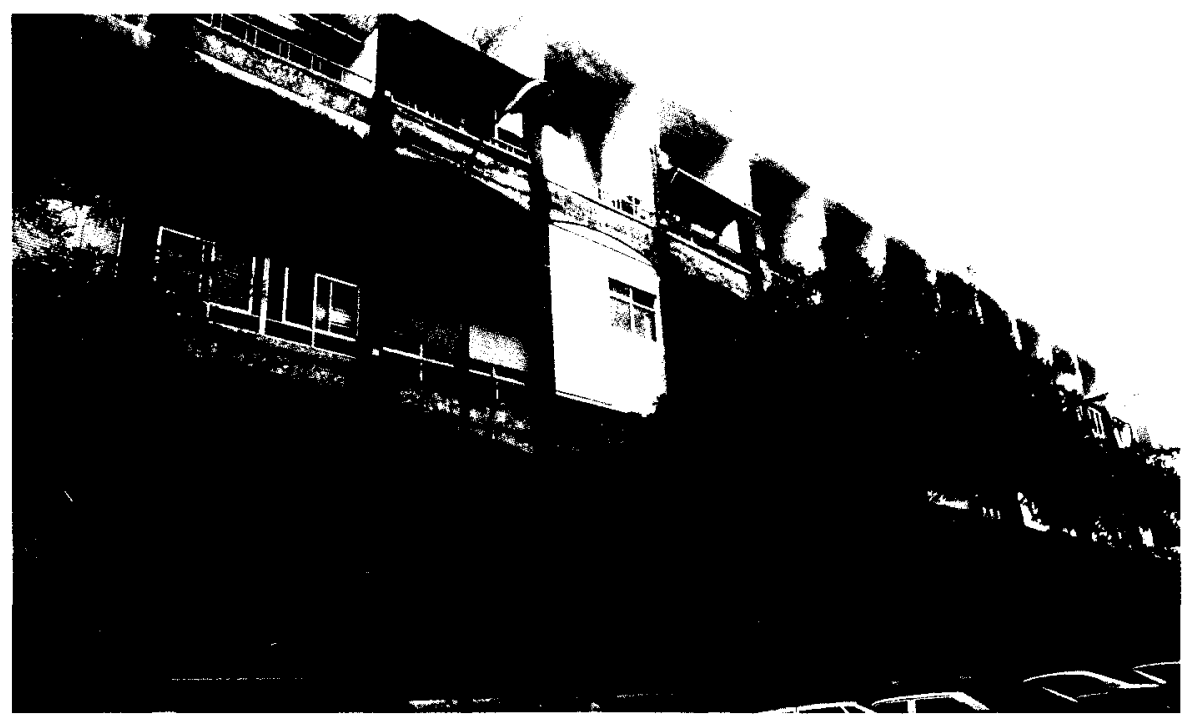

Virgen del Pilar.

no lo compra la empresa, y lo cede a la OSH para que construya viviendas para sus trabajadores. Son ejemplos de colonia obrera al viejo estilo, los usuarios de las viviendas quedan desligados de la ciudad: Virgen de la Paz (para Boetticher y Navarro, S.A.; arquitectos: Ricardo Gómez Abad y José M. ${ }^{a}$ Argote); la Colonia Marconi (arquitectos: José M. ${ }^{a}$ Argote y Joaquín Núñez Mera); en ambos casos son sencillos unifamiliares y pequeñas casas de vecinos de 2 plantas, con corrales en parte posterior. El tercer grupo:

San Carlos / Villaverde

Arquitectos: Joaquín Nuñez Mera, Luis de Sala y Rafael Aburto.

Actuación en dos fases, la segunda, obra de Aburto, sorprende por sus líneas geométricas, casi racionalistas, cercanas a las obras de su compañero Cabrero en el grupo Virgen del Pilar.

\section{La Comisaría de Ordenación Urbana de Madrid}

"... Yo he sentido siempre la tristeza, al entrar a Madrid, de contemplar esos suburbios miserables, esas barriadas que le rodean, esas casas de 


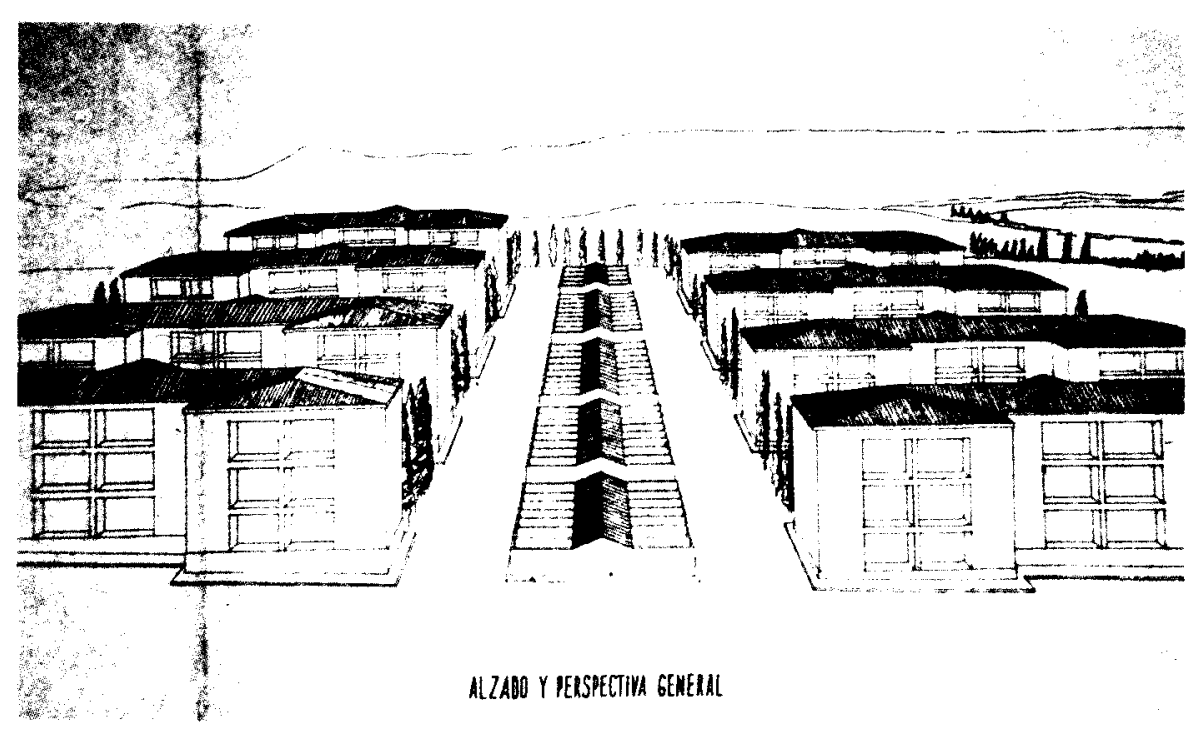

San Carlos / Villaverde.

lata que eran la supervivencia de una ley municipal de más de medio siglo..." (Palabras de Franco al promulgar la Ley de Ordenación Urbana de Madrid) ${ }^{26}$.

El proyecto de Ordenación de Madrid de 1941, obra de Bidagor, necesitó primero la publicación de la Ley de Bases (noviembre de 1944). Su desarrollo y reglamentación se produjo por Ley de 1 de marzo de 1946, la fecha definitiva de la aprobación del Plan General de Ordenación Urbana de Madrid y Alrededores. Esta Ley también disponía la creación de la Comisaría General para la Ordenación Urbana de Madrid y sus Alrededores (COUMA), a la que pasaba a formar parte la Junta de Reconstrucción. Por lo que de nuevo todas las administraciones quedaban representadas en la Comisaría. Su primer director fue Francisco Prieto Moreno (nombrado a la vez Director General de Arquitectura en lugar de Muguruza), que ocupó el cargo desde marzo de 1946 hasta su sustitución por Julián Laguna en mayo de 1954.

Su principal función, una vez aprobado el Plan General, consistía en desarrollarlo con Planes Parciales. Aprobados éstos, la Comisaría se en-

26 Gran Madrid, n. 1, 1948, pág. 5. 
cargaba de dirigir las obras de urbanización de los suburbios, su principal área de actuación (el Ayuntamiento se encargó de las reformas interiores de la ciudad). Ambas entidades habían llegado a un acuerdo de colaboración, fruto del cual se dictaron las Ordenanzas de Edificación en 1946. Así el Ayuntamiento se liberaba de un problema que le había acarreado serias críticas y del que tuvo que defenderse públicamente en varias ocasiones.

En 1948, en el número 1 de la revista Gran Madrid, la publicación informativa de la Comisaría. Prieto Moreno desarrolla una solución teórica al problema de los suburbios. Su teoría consistía en la creación de 30 núcleos (entre 10.000 y 20.000 habitantes), reordenando los existentes y creando otros nuevos. Además, en una singular defensa de las clases modestas, afirmaba que los habitantes de los suburbios son gente digna y trabajadora y achacaba a los anteriores planes urbanísticos el hecho de preocuparse únicamente de la edificación de tipo burgués, olvidando las necesidades de las clases trabajadoras.

Los principios de ordenación de los suburbios mantenían los criterios del Plan de ordenación de Bidagor: delimitación de áreas, perímetros verdes, definición de vías y plazas y dotaciones de servicios comunitarios. Y continuando el debate de la segregación de la clase obrera, apostaba por la convivencia de clases sociales diferentes, además, y esto es importante, por la edificación en densidad. En este artículo, Prieto Moreno explicaba que la labor se iniciaría en los suburbios ya existentes: Tetuán-Norte, Ventas, Puente Vallecas, Usera, Puente de Toledo y Ctra. de Extremadura, (de hecho ya se estaba trabajando en La Ventilla, y en el área de Ventas y el arroyo del Calero en Quintana y Pueblo Nuevo).

La Comisaría no tenía la función de construir y sí ordenar y urbanizar suelo para fomentar la construcción. Su escasa labor constructora se limitaba a realojar a los habitantes de infraviviendas de las zonas a ordenar, como en el caso de la Ventilia y de Ventas. En La Ventilla continúo la labor de la DGA, levantando unifamiliares con corral de aspecto semirural. Mientras que en el área de Las Ventas (Quintana y Pueblo Nuevo) se levantaron algunos bloques de 3 y 4 plantas.

\section{El fracaso de los 40}

Muguruza no se mostraba triunfalista cuando se refería a los suburbios, calificaba las escasas realizaciones como La Ventilla, de «ensayo parcial modesto, ... ¿se volvería a caer en el achaque de la separación de 
clases?» 27. En 1946 (enfermo) abandonaba la DGA, después de criticar la ley de vivienda protegida del INV, constatando la "desproporción entre posibilidades adquisitivas y productoras" que hace imposible adquirir una vivienda a la mayoría de los obreros: "que un obrero sólo gana para comer y hoy no se puede comprar una casa de los metros cuadrados que se considera vivienda protegida, sólo podría pagar una tercera parte de la vivienda oficial»" 28 .

No podemos obviar, al examinar las realizaciones de los años 40 , un cierto aire revanchista, como señalan las duras palabras de Moreno Torres desde Regiones Devastadas al culpabilizar a los suburbios de la "revolución comunista". Por lo que, frente a Muguruza, expone la necesidad de crear ocho grandes barrios-satélites para solucionar el problema de los suburbios. Su propuesta apoya la segregación espacial a través de anillos verdes, como en la Ley de 1946. Moreno Torres apunta la necesidad de separar la clase obrera para debilitarla y controlarla, en estos núcleos sólo el $25 \%$ debía ser clase obrera (de un total de 20.000 personas en cada barrio-satélite), que ocuparían 1.000 viviendas en 4 ó 5 grupos convenientemente «diseminados» 29 .

Aparte de la postura de Muguruza, una de las primeras críticas a la Ley de 19 de abril de 1939, apareció ya en 1940: "los beneficios que concede a las viviendas protegidas son más reducidos que en la legislación anterior, y esto lo consideramos un error.» (Iradier García, perteneciente al equipo del alcalde de Madrid). «Es al Estado al que corresponde hacer el mayor esfuerzo y sacrificio.... su apoyo no es todo lo intenso que fuera de desear... no hay posibilidad de que organizaciones locales y sindicales puedan por sí solos abordar el problema,... no se puede esperar de la iniciativa privada la resolución del problema» ${ }^{30}$.

Habrá que esperar al final de la década, como ha señalado Sambricio, cuando la arquitectura realice una aportación fundamental buscando ofrecer nuevas soluciones al problema. Soluciones que pasaban por establecer mínimos de vivienda que retoman el "debate racionalista de los años anteriores a la guerra", y que recuperan las ideas de estandarización y prefabricación, y la investigación tanto arquitectónica como industrial.

EEguez, S.: Op. cit. págs. 154-155

28 Muguruza, P.: La vivienda de las clases modestas. Sus condiciones minimas de habitabilidad. Conferencia pronunciada en la congregación de San Luis Gonzaga, Madrid, 30 de enero de 1946.

29 El Futuro Madrid..., págs. 15-27

30 Ponencia de Iradier Garcia, en el / Congreso..., pág. 219. 
Aparcando el problema urbano para atender primero el más elemental de la vivienda ${ }^{31}$.

Los arquitectos de la OSH y el INV observaron los modelos europeos de reconstrucción; además surgen ahora aportaciones interesantes como el estudio de vivienda económica que Bastida y Amánn presentan a la $V$ Asamblea de Arquitectos (1949); los concursos que premian la investigación arquitectónica (como el del Instituto Torroja, 1949; o el del Colegio de Arquitectos de Madrid en 1949, con las viviendas en cadena de Fisac); o el Estudio sobre vivienda económica de Giralt Casadessús (1949).

Sólo a mediados de los 50 el Estado entenderá, porque el problema social cobra tales magnitudes, que debe dejar de inhibirse. Entonces, el precio a pagar será sacrificar una parte del Plan de Bidagor, las áreas calificadas como verdes o rústicas, devoradas por el chabolismo. Como señala Sofía Dieguez, el Plan de 1941 dejaba de cumplir «el objetivo para el que habia sido redactado: ordenar el crecimiento de la ciudad» 32 .

\section{RECUPERACIÓN ECONÓMICA Y NUEVA POLITICA DE VIVIENDA (1951-1956)}

En 1953 España y Estados Unidos reforzaron sus lazos de cooperación interesada al firmar los acuerdos de colaboración. El mismo año que se firmó el Concordato con la Santa Sede, ratificando el cambio de rumbo que había llevado al país desde el nacional-sindicalismo falangista hacia el nacional-catolicismo.

Además, en 1951, Franco habia remodelado el Gobierno, dando entrada a ministros más favorables a cierto grado de liberalización económica (en 1950, España aún no había recuperado los índices económicos anteriores a la Guerra Civil). Los indicadores socioeconómicos de España en 1950 eran propios de un país subdesarrollado, como Grecia y Portugal en Europa, e incluso peores que algunos países sudamericanos. El ajuste de 1951 «No es un proyecto planeado, y sí la rendición al fracaso de la autarquía» ${ }^{33}$.

A lo largo de estos diez años la población española creció en dos millones y medio de habitantes, y el mapa de la población activa continuó incrementando el sector industrial y el de servicios en detrimento del agrario. Este pro-

\footnotetext{
Sambricio, C.: Op. cit., págs. 26-33.

DiÉGuez, S.: Op. cit., pág. 165.

Barciela et al.: Op. cit., pág. 162.
} 
ceso conllevó una masiva emigración rural, con una media anual para la década de los 50 de 229.000 personas que abandonaban el campo para asentarse en la ciudad, frente a los 105.000 de media de la década anterior. A partir de 1951 la industria comenzó a liderar el crecimiento económico, y en 1953 se consiguieron sobrepasar los índices de productividad de los años 30 .

\section{El proyecto de poblados satélites de la Comisaria}

En 1950 la Comisaría no sólo no había conseguido frenar la infravivienda en el suburbio, sino que en el área del extrarradio el chabolismo continuaba ganando terreno. El Plan de Poblados Satélites de 1950 preveía cinco enclaves que comprendían 235 ha. y la creación de 27.000 viviendas en Manoteras, Canillas, San Blas, Palomeras y Villaverde. Los enclaves se encontraban en nudos industriales y de comunicaciones y se preveía una importante dotación de servicios para convertirlos en núcleos autónomos de la ciudad. En 1952 el Plan se amplía y a estos cinco enclaves se añaden Peñagrande, Vicálvaro y Carabanchel; completando una corona de poblados satélites alrededor de la capital.

El primer poblado se instalaría en el Cerro de San Blas, con 1.170 viviendas. En 1952 se construyen 96 albergues para los expropiados del arroyo Abroñigal (puente de Ventas), que se deciden transformar en viviendas definitivas al año siguiente, pero que en 1954 aún no están ocupadas. A la vez se anuncia una segunda fase para terminar el grueso principal del proyecto, pero el INV y Regiones Devastadas no se ponen de acuerdo y toda la iniciativa queda anulada y absorbida por la posterior etapa de poblados dirigidos.

Prieto Moreno presentaba su dimisión en 1954 y fue sustituido por Julián Laguna, presidente de la Junta Superior del Colegio de Arquitectos de España (donde sustituyó a Muguruza, fallecido en 1952), a designación del Ministro de Gobernación. Laguna dirigirá los planes de la Comisaria de los poblados, renovándolos y ampliándolos, dirigiendo la etapa más fructífera de generación de vivienda desde el final de la guerra.

\section{E! Plan Nacional de Vivienda de 1955: el cambio de legislación}

Si la propuesta de la Comisaría del plan de poblados satélites fracasó, lo fue en gran medida porque aún se mantenía el marco legal de vivienda protegida dictado por el INV en 1939. En 1951, tras un año de estudios, una Comisión Interministerial que preside el Ministro de Gobernación en- 
trega al Gobierno las conclusiones de un informe que estudia el problema de la vivienda en todo el país ${ }^{34}$. Para resolver el problema a "corto plazo" (20 años) se necesitan construir 76.000 viviendas al año en toda España. Viviendas distribuidas en tres categorias: la primera, asumible por la iniciativa privada; la segunda correspondía a viviendas para clase media; y la tercera categoría requería la subvención directa del Estado (mas una política municipal de compra y urbanización de suelo en zonas de extrarradio urbano, el cual los ayuntamientos cedieran a bajo precio o incluso de forma gratuita).

Respecto a la distribución, el informe presentaba las conclusiones de las investigaciones de la DGA en los suburbios de Madrid: el $50 \%$ de las familias puede alojarse en viviendas de 2 dormitorios, el $35 \%$ necesitan 3 ó más, y el $15 \%$ tienen bastante con uno. Esta propuesta ya no hace referencia a las ideas de 1939 sobre la importancia y necesidad de separación entre sexos en bien de la moral (lo que suponía un incremento del número de habitaciones inasumible en el coste de adquisición de una vivienda modesta).

Respecto a la financiación el Informe era tajante: «...canalizar de nuevo una parte del ahorro nacional, antes muy considerable, hacia la producción de viviendas", pasando de los 2.000 millones de pesetas anuales hasta los 4.500 necesarios. "Se precisa una ordenación de los gastos del Estado que permita dedicar una cantidad a fondo perdido...el clima de gravedad en que entra el problema da pie político para ello. Su importancia va desbordando la de otros problemas nacionales". Lo último que resalta el Informe, hace referencia al aspecto constructivo de las viviendas más "modestas»: la autoconstrucción. La experiencia aportada por entidades benéficas, eclesiales y municipales se valoraba muy positivamente. En la conclusión del Informe se determina que la acción directa del Estado debe quedar exclusivamente para los casos más extremos.

La VI Asamblea Nacional de Arquitectos, celebrada en este momento, aportará también algunas ideas y conclusiones: una velada llamada al racionalismo, al funcionalismo y a la austeridad constructiva; la necesidad de un "plan de urgencia" de construcción de 70.000 viviendas anuales; y la gestión por parte de un único organismo rector "de suficiente categoría administrativa y capacidad coordinadora» (un ministerio de la vivienda) ${ }^{35}$.

\footnotetext{
34 Los resultados del análisis de esta Comisión se publican resumidos en el Boletín de Información de la Dirección General de Arquitectura, n." 18, 1951, págs. 3-7.

Reconstrucción, n. 115, 1953, págs. 34-35.
} 
Como consecuencia del Informe ministerial en 1954 se formula la nueva legislación en materia de vivienda: Viviendas de Tipo Social (Decreto-Ley de 14 de mayo de 1954; superficie máxima de $42 \mathrm{~m}^{2}$ y 25.000 pesetas de coste; se necesitan 100.000 viviendas de tipo social al año, a planificar por el INV y construidas por cualquier entidad promotora sin ánimo de lucro con preferencia expresa de la $\mathrm{OSH}$ ); viviendas de Renta Reducida y Mínima (Decreto-Ley de 29 de mayo de 1954; superficie según 4 categorías, $74,80,90$ y $100 \mathrm{~m}^{2}$; coste variable entre 74.000 y 100.000 pesetas; se necesitan 20.00 viviendas de estas características al año, a construir exclusivamente por la OSH en colaboración con el INV); viviendas de Renta Limitada (Ley de 15 de julio de 1954; refunde las anteriores viviendas protegidas — 19 de abril de 1939, INV - y las bonificables — noviembre 1944/1948-).

Con esta legislación se cumplía el objetivo expuesto por el Ministro de Gobernación ante la VI Asamblea de Arquitectos: detener la actividad constructora oficial para sólo actuar donde no llegue la iniciativa privada, siempre en caso de beneficencia estatal.

\section{La experiencia de la autoconstrucción en las Asociaciones Benéficas}

La más antigua de estas asociaciones, la Fundación Mariano Lanuza, erigió un grupo de viviendas a finales de los años 40 en terrenos de la Ctra. de Extremadura cercanos a las actuaciones del PMV (diseñadas por el arquitecto Ignacio de Aldama, académico de Bellas Artes de San Fernando). La Fundación se constituyó en 1944 con el objetivo específico de construir viviendas económicas para familias «obreras y cristianas». Los requisitos para obtener una vivienda: «no tener antecedentes penales y gozar de buena fama en el aspecto moral, religioso y patriótico »; por lo que la documentación a aportar para solicitar la vivienda requería partida de bautismo y de boda y una certificación del párroco local en la que se "garantizase" la buena moral del individuo. El coste de la vivienda suponía el estricto coste de la construcción. Las viviendas, de $90 \mathrm{~m}^{2}$, se componían de vestíbulo, comedor-cocina, aseo con ducha y galería con pila y fregadero, en bloques de cuatro alturas con caja de escalera para cada par de viviendas ${ }^{36}$.

La más importante de estas asociaciones, la Real Congregación de Arquitectos de Nuestra Señora de Belén en su Huida a Egipto, estaba cons-

36 Archivo Dirección General Arquitectura, Vivienda y Urbanismo, expediente M-3007-VP. 

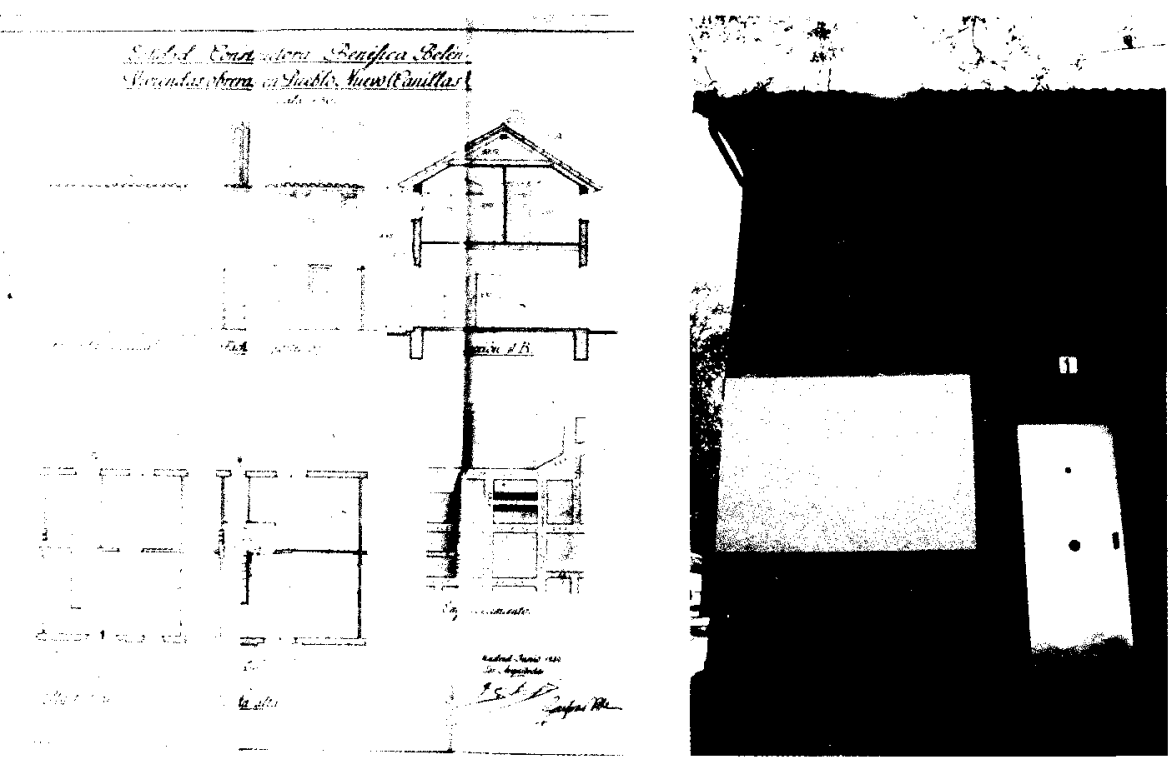

Belén / Pueblo Nuevo.

tituida sólo por arquitectos: Gaspar Blein (Presidente), Luis Laorga, Germán V. Gamazo Garcia-Noblejas, González de Riancho, Javier Lahuerta, Sánchez Conde y J. Ramón Caso Corral.

\section{Belén / Pueblo Nuevo}

Arquitectos: Gaspar Blein y Luis Laorga.

Pequeños grupos de viviendas de máxima sencillez, edificados por y para obreros de la construcción, que con su «prestación personal» abarataban el coste final de la obra. Unifamiliares en hilera de 1 ó 2 plantas, con tapial de ladrillo a fachada, tejado a dos aguas, y patio posterior. Su sencillez enlaza con la tradición ruralista de los poblados de la DGA y Regiones Devastadas de la década de 1940, nada que ver con las aportaciones de los poblados de absorción y los dirigidos. Esta Sociedad fue declarada "entidad constructora" por Decreto de 20 de marzo de 1950 , con lo que gozaba de los beneficios del INV en materia de financiación de las viviendas.

Por otro lado, la Constructora Benéfica Asociación Caridad, promovida por aristócratas filántropos desarrolló su actividad en el área del Puente de Vallecas proporcionando viviendas, según sus estatutos a "clases modes- 
tas", gracias también a la colaboración desinteresada de algunos arquitectos. Declarada "entidad constructora" en 1949, también se basaba en el sistema de autoconstrucción, para levantar unifamiliares de 1 y 2 plantas en hilera con patio de aspecto ruralizante, y bloques en T de 3, 4 y 5 plantas.

El Patronato Madrileño Virgen de la Almudena se constituyó a finales de 1951 por iniciativa del Obispo de Madrid Eijo Garay. Se financiaba gracias a suscriptores particulares, a donativos (como los dos millones de pesetas que aportan Juan March y el General Trujillo), y a tómbolas benéficas. Sus dos actuaciones son la Colonia Virgen de las Gracias (situada en la zona de Oporto, obra de los arquitectos Carrión Aizpurúa y Bastarreche); y la Colonia Patriarca Eijo Garay (en el Barrio Lucero; obra de Bastarreche). En ambos casos son bloques cerrados con patio interior de 2, 3 y 4 plantas, y bloques de doble crujía de 4 plantas. Viviendas mínimas de baja calidad constructiva y reducidas superficies.

Por Decreto de 18 de mayo de 1951 el Gobierno creaba un plan de 10.000 viviendas para obreros y empleados de las empresas y entidades oficiales que integraban la Constructora Benéfica Hogar del Empleado. Dos años más tarde, en diciembre de 1953, el INV era encomendado para la construcción directa de 5.000 de estas viviendas. La principal actuación fue Nuestra Señora de Lourdes/Unidad Vecinal Batán (diseño de los arquitectos Sáenz de Oiza, Sierra y Romany).

\section{El INV y el II Plan Nacional de la Vivienda}

Después de quince años en el cargo, Federico Mayo, director del INV (y a la vez de la OSH), fallece a finales de 1954; el sustituto para ocupar su puesto, Luis Valero Bermejo, ocupó el cargo de gobernador civil en Ávila y Navarra. Valero es designado por Franco y de él se conoce su larga experiencia en la promoción de viviendas desde su puesto de gobernador, promoviendo el sistema de la autoconstrucción (“prestación personal»).

Después de la aprobación de las nuevas categorías legales de vivienda de 1954 restaba por ser aprobado el Reglamento, lo que se realiza en 1955, a la par que el II Plan Nacional de la Vivienda (Decreto de 1 de julio de 1955), que preveía la construcción de 550.000 viviendas en cinco años (110.000 al año) ${ }^{37}$. El Plan incluía un Decreto que autorizaba al INV a desarrollarlo en Madrid.

37 Una cifra impensable hace apenas unos años (el Informe de la Comisión Interministerial estimaba en 1951, la necesidad de construir 76.000 viviendas anuales para paliar la escasez de vivienda). 
La importancia del Reglamento radica en la «transparente voluntad de construir la vivienda funcional, desde la exigencia obligada de la doble crujía en los bloques de los nuevos núcleos", la prohibición de cualquier obra adicional de carácter decorativo y el excesivo movimiento de plantas, es decir, "todo cuanto sin necesidad funcional encarezca innecesariamente la construcción» ${ }^{38}$. El Reglamento también formulaba establecer concursos entre equipos formados por arquitectos y empresas, con la finalidad de adjudicar entre los ganadores la construcción de viviendas. El único concurso que se llevó a cabo, lo convocó el INV ese mismo año de 1955.

Al igual que ocurrió con el I Plan Nacional de la Vivienda 1944-1954, este II Plan tampoco consiguió cumplir sus objetivos, sólo se construyeron la mitad de las viviendas programadas. Aunque sí que se edificaron 512.000 viviendas, pero de una categoría superior, lo que no satisfacia las demandas reales de la población, pero demostraba el interés de la industria de la construcción y el capital privado ${ }^{39}$.

Una actuación directa del INV fue la conclusión de un proyecto anterior del Ayuntamiento de Vallecas, la Colonia Nuestra Señora del Perpetuo Socorro. Bloques en altura de 5 plantas, actuación de una escala importante para el momento, 1.400 viviendas de arquitectura repetitiva, con bloques-manzana en torno a un patio, y bloques de doble crujía.

\section{El primer Plan Sindical de la Obra Sindical del Hogar (OSH), 1954-1955}

La aprobación del Decreto-Ley de 29 de mayo de 1954, viviendas de Renta Reducida y Mínimas, concedía en exclusividad a la OSH la misión de erigir un Plan propio de vivienda. La OSH pone en marcha el Plan Sindical "Francisco Franco" para el período 1954-1960, el I Plan correspondía al ejercicio 1954-1955.

El Decreto asignaba a la OSH, en colaboración con el INV, la construcción de 20.000 viviendas por año, para "productores" encuadrados en la organización sindical. El Plan Sindical determinaba los tipos de vivienda de renta mínima y de renta reducida. La OSH estableció unas características comunes a todos los grupos a proyectar en lo referente a materiales, sistema constructivo, contratas, documentación, plantas tipo,

\footnotetext{
38. Fernandez-Galiano, ISASI y Lopera: La quimera moderna. Los Poblados Dirigidos de Madrid en la arquitectura de los 50. págs. 16-21. Madrid. H. Blume, 1989.

39 Mova González, L.: Op. cit., pág. 37.
} 


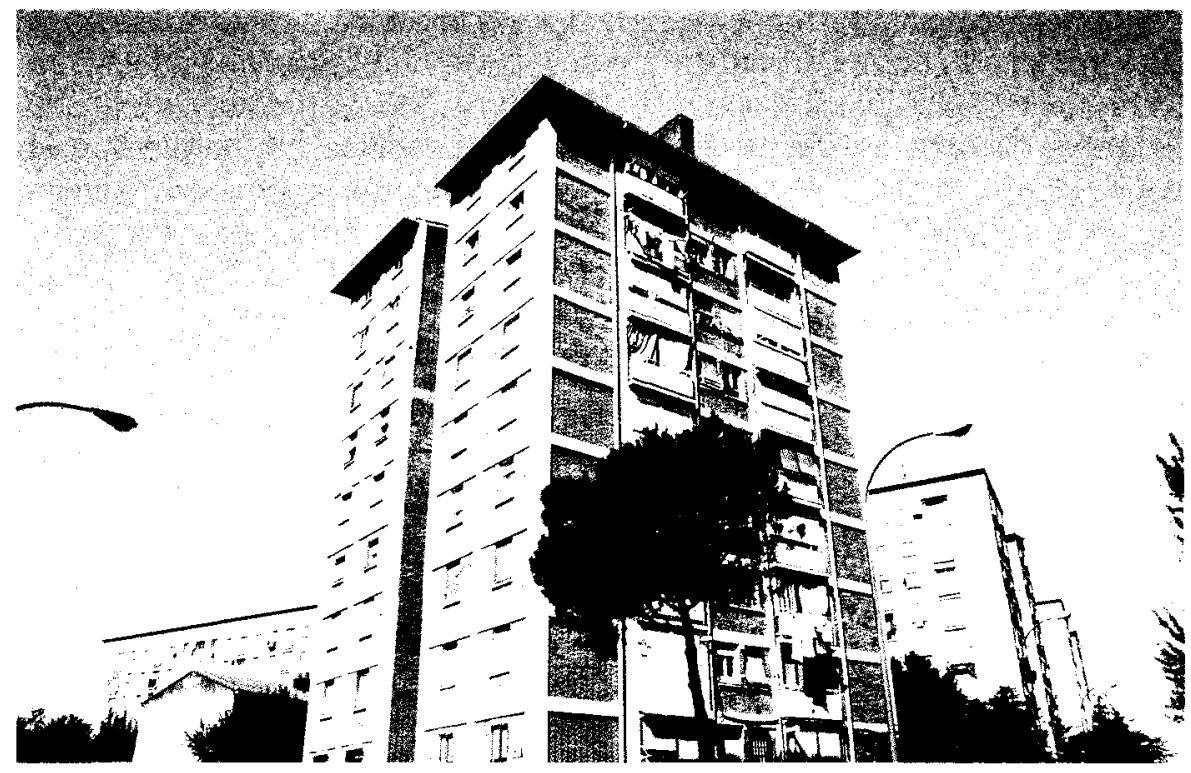

Nuestra Señora del Carmen (Quintana).

agrupaciones tipo (preferentemente en malla racional/ortogonal, o irregulares si el terreno lo exigía).

Las viviendas reducidas y mínimas de este I Plan fueron diseñadas por el grupo de arquitectos de la organización: Cabrero, Aburto, Argote, Núñez Mera y Benlloch. Se construyeron cuatro grandes grupos de similares características: Francisco Franco (San Blas), San Nicolás (Dehesa de la Villa), Experimental de Villaverde / Colonia San Carlos (Villaverde Alto) y el grupo que sirve como ejemplo:

\section{Nuestra Señora del Carmen (Quintana)}

Las cuatro actuaciones responden a un único criterio tipológico: torres en $\mathrm{H}$ o en doble crujia de 10 o 12 plantas, y bloques de doble crujia de 4 y 5 plantas. El diseño de los edificios es el mismo en las cuatro localizaciones diferentes. La importancia de esta actuación de la OSH radica en la determinación con la que actúa al elegir la construcción en altura como solución al problema de la vivienda.

Las viviendas de tipo social, con un máximo de $42 \mathrm{~m}^{2}$, fueron consideradas en algún momento Poblados de Absorción, por lo que su trazado y 
tipología tienen coincidencias con los erigidos por la OSH. Estos grupos se levantaron en el Zofío (2 fases; arquitectos: José M. ${ }^{a}$ Argote y Miguel Fisac); Vista Alegre (Colonia Pan Bendito, Carabanchel; arquitecto: Mariano Rodríguez Avial); Canillas (Ctra. Canillas; arquitecto: Federico Faci). Su variedad tipológica y urbanística responde a las actuaciones individuales de los arquitectos elegidos, no como la uniformidad que reúnen las viviendas de renta reducida y mínima, tanto en unifamiliares en hilera como en bloques de 4 ó 5 alturas, generalmente de doble crujía.

\section{La política de Poblados}

Desde 1954-1955, con la nueva legislación de vivienda (tipo social, renta limitada y reducida, y mínima), juntamente al Plan de la Vivienda del INV y al Sindical de la OSH, se aprueba una nueva política de poblados, con la participación de jóvenes arquitectos españoles, que desgranará uno de los mejores capítulos de la vivienda social española.

Las nuevas tipologías de poblados fueron las siguientes: Poblados Dirigidos (absorción de emigración, venta en propiedad, «prestación personal»); Poblados de Absorción (alojo del chabolismo; alquiler; carácter provisional - sin embargo permanecieron en el tiempo-, proyectados en 1954, en 1956 algunos ya se encontraban terminados): Poblados Mínimos (viviendas temporales de dimensiones mínimas y servicios elementales); Poblados Agrícolas (alquiler; patio trasero para usos agrícolas).

El planteamiento original de la política de poblados es diseño de Julián Laguna al poco de hacerse cargo de la Comisaría en 1954. No deja de ser una reelaboración más detallada del antiguo plan de ciudades satélites del Plan de Bidagor de 1946, y del fracasado intento de poblados satélites de la propia Comisaría en 1951. La propuesta original de Laguna tampoco se completó del todo, pues se quedó solamente en la creación de los poblados dirigidos y de absorción. En el planteamiento original existían una tercera y cuarta fase con el diseño de "Nuevos núcleos urbanos" (actuación de categoría superior a los poblados dirigidos), y los "Barrios-tipo" (creación de una estructura completa de viviendas y servicios de cierta entidad).

Se preveía construir 15 poblados (13 de absorción y 2 mínimos) con un total de 12.086 viviendas. El resultado final, 12 poblados, obtuvo la colaboración de la OSH, la COUMA y el INV, el Ayuntamiento de Madrid, y el Gobierno Civil, con 9.886 viviendas. 

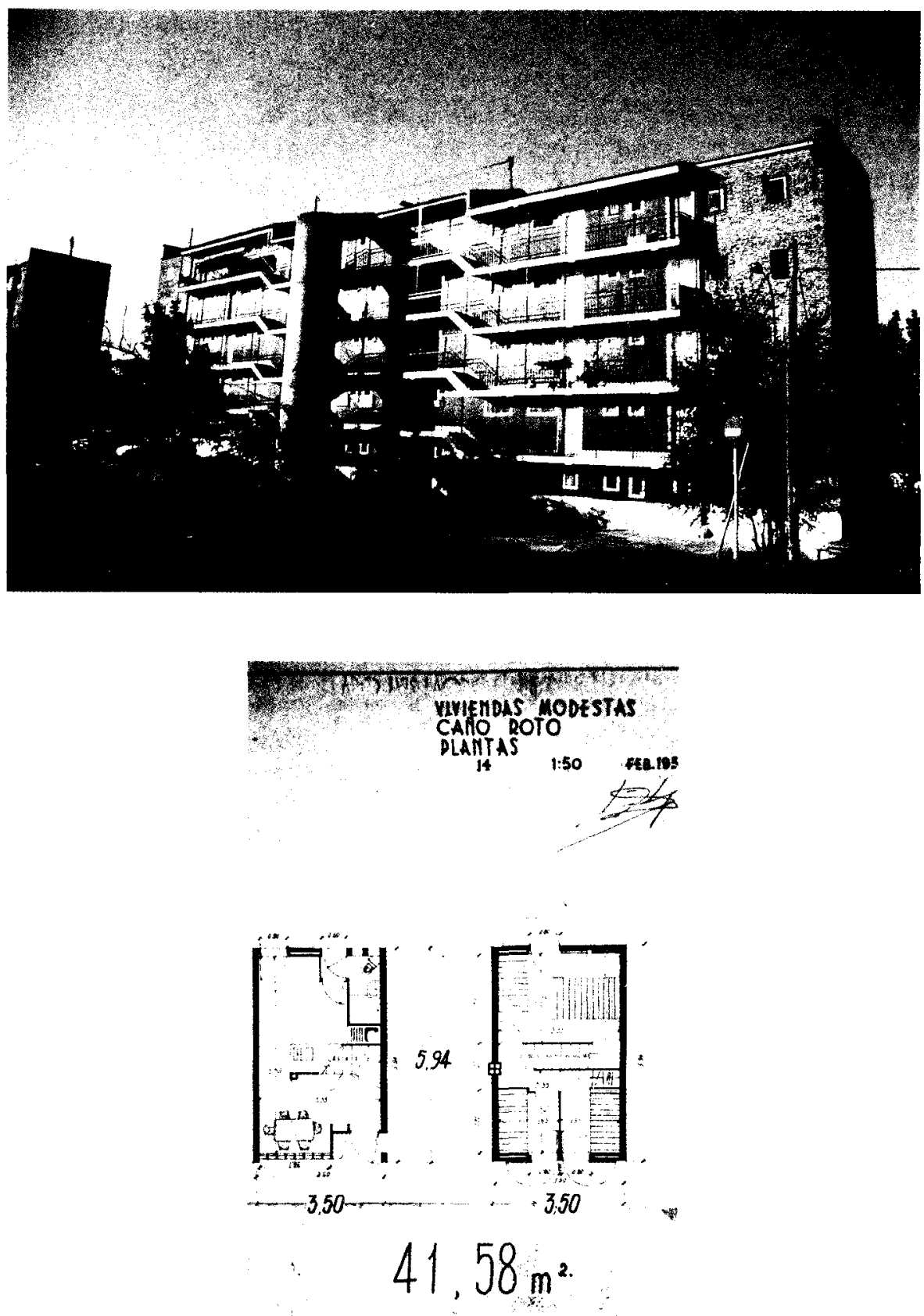

Poblados de absorción. 


\section{Poblados de absorción}

Tres poblados se ejecutaron desde la OSH: Fuencarral A (diseñado por Sáenz de Oiza), Fuencarral B (obra de Alejandro de la Sota) y Caño Roto (del arquitecto Luis Laorga). El resto fueron diseñados desde el INV y la Comisaría: San Fermín, San Blas I, San Blas II, Entrevías y Orcasitas. Fuencarral $A$ y $B$ se convirtieron en el banco de pruebas de esta experiencia. Oiza y De la Sota propusieron diseños de unifamiliares y de bloques de cuatro alturas basados en la racionalización absoluta de plantas, distribución y elementos constructivos y arquitectónicos. El poblado de Oiza fue el elegido por Valero y Laguna como ejemplo, mientras que la propuesta de De la Sota les pareció demasiado cercana al ruralismo del que pretendían huir.

Poblados dirigidos

En el verano de 1956, al encontrarse ya en marcha los poblados de absorción, Valero y Laguna decidieron comenzar la segunda fase de su política de poblados iniciando los poblados dirigidos. Se utilizó en muchas ocasiones el suelo contiguo a ios poblados de absorción que había sido despejado y expropiado para aquella operación. En los poblados dirigidos las viviendas se acogieron a la categoría de "renta limitada" (no el «tipo social" de los poblados de absorción), y el destinatario final debía colaborar en su construcción (el denominado sistema de "prestación personal»).

El primer proyecto de poblado dirigido (Entrevías, donde la situación de chabolismo era desproporcionada) se encargó al grupo Oiza, Sierra y Alvear. Además de Entrevias se iniazaron en este momento los poblados dirigidos de Canillas (obra de Luis Cubillo), Fuencarral (José Luis Romany), Caño Roto (Antonio Vázquez de Castro y José Luis Íñiguez de Onzoño) y Orcasitas (Rafael Leoz y Joaquín Ruiz Hervás). En 1957 se encargó el poblado dirigido de Manoteras (a los arquitectos Ambrós, Garcia Benito, García Rodríguez y Quereizaeta), y en 1959 el de Almendrales, acogido ya a la nueva legislación de 1957 (obra de Javier Carvajal, Vázquez Molezún,

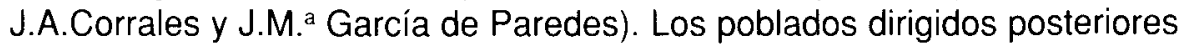
nada tuvieron que ver con estos ejemplos anteriores, pues la salida de Laguna y Valero, junto a la nueva política del Ministerio de la Vivienda, apartó a los arquitectos que habían colaborado en la etapa de 1956, y su estética arquitectónica y características constructivas discurrieron por otro camino.

Estos poblados suponen el punto álgido en la aportación de la arquitectura española a la vivienda social en todo este período. Los arquitectos aportaron en la mayoría de los casos una plasticidad, un lenguaje y una estética de alto valor. La mayoría de las actuaciones se constituyen de vi- 


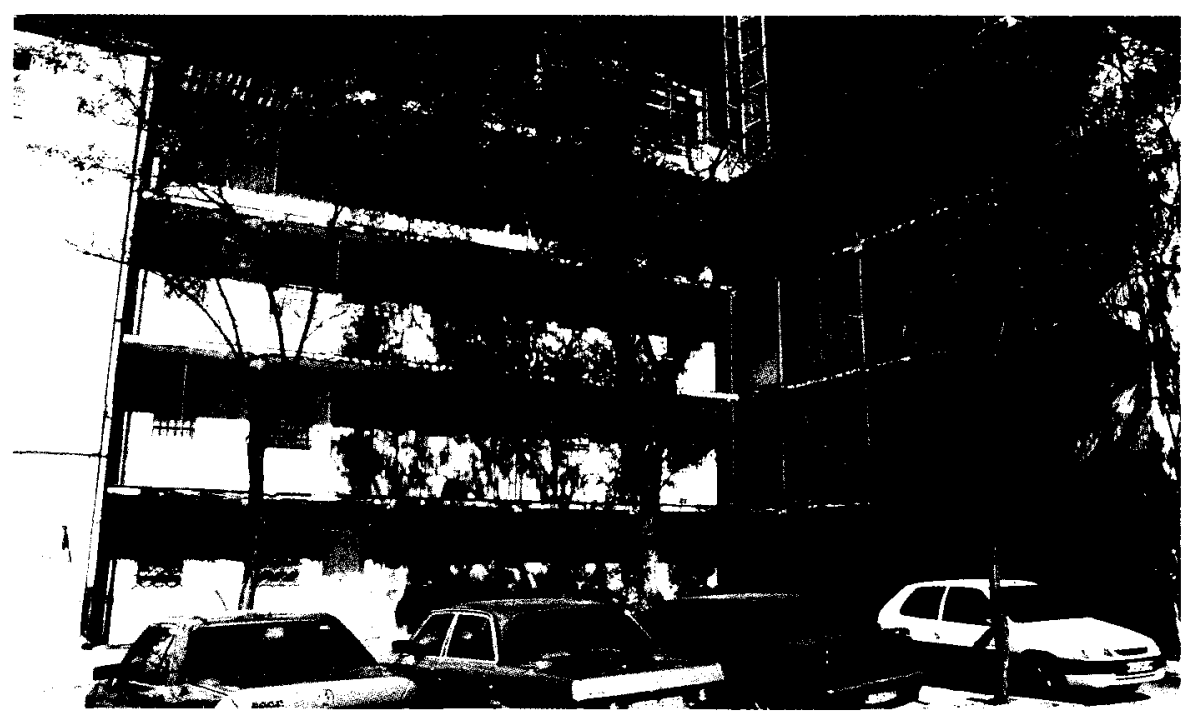

Viviendas Municipales: Puente de Vallecas.

viendas unifamiliares en hilera de 1 y 2 plantas y bloques de 4 y 5 plantas, alejados del pintoresquismo y el folklorimso anterior, $y$ tomando formas abstractas, minimalistas, brutalistas o neoplasticistas ${ }^{40}$.

\section{Otras actuaciones}

En 1950 el Ayuntamiento de Vallecas, antes de su anexión a Madrid, planteó una actuación sorprendente por la escala de la intervención: 8 poblados, con unas 3.000 viviendas en áreas del Puente y Villa de Vallecas. El alcalde vallecano recibió el permiso de la Comisaría y del INV, y la declaración de urgencia de las obras por decreto del Ministerio de Trabajo. Tras la anexión de Vallecas, el Patronato Municipal de la Vivienda (PMV) se hizo cargo, junto al INV, de la finalización de los grupos. Todos reúnen las mismas características: sencillez máxima, bloques de 4 y 5 plantas de doble crujía o con galería corredor al exterior (similares a las actuaciones de la PMV en la década de los 40).

Por su parte el Instituto Nacional de Industria (INI) en colaboración con el INV realizó grupos y colonias para los empleados de aquella institución.

40. Como ha señalado Fernandez Galiano: Op. cit., pág. 41. 
Como el Poblado ENASA/PEGASO (en la N-II, obra de Juan Bautista Esquer y Francisco Bellosillo); o el Poblado Iberia / Nuestra Señora de Loreto (en el pueblo de Barajas; arquitecto: Fernando Montes Rodríguez). Actuaciones en forma de poblado, con diferentes calidades de viviendas según el rango laboral. La Colonia Loreto aún recuerda el aire ruralista de los 40, sin embargo Pegaso elige un tipo de vivienda en altura mucho más actual. Con la novedad de la estructura hexagonal en planta, en vez de la típica manzana cuadrada.

\section{VEINTE AÑOS PERDIDOS (1957-1959)}

En el año 1956 la tensión entre las familias del Régimen desata una nueva remodelación de gobierno. En medio de un clima de tensión social y creciente descontento, el Ministro de Trabajo (Girón, falangista que ocupó este sillón entre 1941-1957) aprueba un incremento de los salarios del $20 \%$. Sin embrago, al no reducirse la tensión, Franco se vio obligado a remodelar de nuevo el gobierno en 1957, Arrese (Secretario del Movimiento) es "desterrado" al recién creado Ministerio de la Vivienda, (hasta su dimisión en 1960). Arrese no fue el único en perder protagonismo, los viejos católicos y monárquicos se vieron desplazados por los hombres del Opus Dei, los "tecnócratas", que tomaron las riendas de la política económica, y en 1959 presentan el Plan de Estabilidad. «El giro de la política económica de 1959 se fundamentó en la aceptación de la economía de mercado preponderante en el mundo occidental" ${ }^{41}$.

Los efectos del Plan fueron sorprendentemente rápidos, el llamado «milagro económico español» (expresión que no tiene en cuenta la favorable coyuntura económica internacional). Pero la parte más dura de la repercusión de las medidas del Plan recayó sobre la sociedad, pues provocaron un período de recesión económica, el incremento del paro y la caída de la renta per cápita.

La creación del Ministerio de la Vivienda: «ni un español sin pan, ni una familia sin hogar"

El Ministerio de la Vivienda, instituido por Decreto Ley de 25 de febrero de 1957, debía agrupar el INV, la Dirección General de Arquitectura y

41 Barciela et al.: Op. cit, pág. 178. 
Urbanismo, y la Dirección General de Regiones Devastadas (que desaparecen después de casi 20 años de trabajos). La nueva Dirección General de la Vivienda, que acogió al INV, fue dirigida por Vicente Mortes, sustituto del cesado Luis Valero. Para la Dirección General de Urbanismo se eligió a Pedro Bidagor, quien veía refrendada su labor a lo largo de dos décadas dedicadas al Urbanismo, y cuyas teorías se plasmaron en la Ley del Suelo de 1956. La Dirección General de Arquitectura, recayó en J.A. Bringas, concejal del Ayuntamiento de Madrid, y su representante en la Comisaría de Urbanismo de Madrid (organismo que también pasó a depender del nuevo ministerio, sin Julián Laguna, quien habia presentado su dimisión).

La nueva política radicaba en entregar a la iniciativa privada las herramientas jurídicas y financieras para desarrollar la construcción de vivienda social, convirtiéndolo en negocio rentable. Lo que reflejaba el cambio de la política económica franquista, al eliminar también en este terreno el intervencionismo, abriéndose a la regulación del mercado. Arrese promovió la vivienda en propiedad frente al alquiler, y apoyó la máxima rentabilidad del sector privado. Esta nueva política derivó en una arquitectura especulativa que favorecía la construcción en torre (viviendas de hasta 13 alturas), frente a la política de poblados y su reparto del terreno en unifamiliares.

Vicente Mortes, estimaba el déficit de viviendas en 1.200 .000 (con un ritmo anual necesario de 140.000). A los arquitectos les conminaba a "mirar por la economía del suelo, del dinero, de materiales, pero no de la belleza (...) tenemos una superficie media de la vivienda excesiva en España (...) tenemos que acomodar el coste de la vivienda a las posibilidades adquisitivas de nuestras gentes más modestas»" ${ }^{42}$. Frente a las posibilidades arquitectónicas de la política de Valero y Laguna en los poblados, ahora se remarca el objetivo económico, sin experimentar, ajustando el diseño a los mínimos módulos económicos que el capital privado considera rentables. Con la entrada del capital privado serán las inmobiliarias, como señala Sambricio, las que marcarán el futuro del urbanismo ${ }^{43}$.

\section{El Plan de Urgencia Social}

Aprobado el 13 de noviembre de 1957 junto a la Ley de Viviendas Subvencionadas, la misión del Plan consistía en levantar 60.000 viviendas en

42 Revista Nacional de Arquitectura., n. 198, junio 1958, págs. 19-26.

43 Sambricio: Op. cit., págs. 69-70. 
dos años "para resolver no la parte normal de un crecimiento ordinario, sino aquella otra que a lo largo de unos años se ha ido acumulando sobre nuestra capital» ${ }^{44}$.

El Plan iba acompañado de medidas policiales para frenar la inmigración y los asentamientos ilegales. Su desarrollo perseguía obtener la participación de la iniciativa privada junto a la economización máxima en materiales, mano de obra y suelo. La Ley preveía poner un punto final al crecimiento de Madrid (y retomar la idea del anillo verde), con un Plan de Descongestión Industrial de Madrid, por el que se fomentaba la creación de polígonos industriales en un amplio radio en torno a Madrid (Aranjuez, Alcalá de Henares, Ocaña, ... y Aranda de Duero). Plan que no tuvo apenas fortuna. No así el Plan de Urgencia Social, que se convirtió en el mayor éxito en política de vivienda del Régimen.

\section{El II Plan Sindical de la OSH}

Hasta el año 1960 la Obra Sindical del Hogar (OSH) construyó 30 grandes grupos de viviendas sociales en Madrid, 13 de los cuales se asentaron sobre "zonas verdes" y tuvieron que ser "legalizados"en la reordenación urbanística por Decreto de 1963. La superficie habitable de las viviendas de la OSH fue sufriendo una merma si comparamos las realizaciones hasta 1954 (60 y $70 \mathrm{~m}^{2}$ ), frente a las superficies de los Planes Sindicales, que al acogerse en un $75 \%$ a la categoría de "tipo social» ofrecian viviendas inferiores a los $42 \mathrm{~m}^{2}$ establecidos por ley. La distribución interior se mantuvo, lo que perjudicaba a sus usuarios, al no mantener una mínima funcionalidad. La calidad constructiva, la orientación y la localización también fueron perdiendo calidad. El II Plan Sindical (1956-1957) preveía 50.000 viviendas para todo el territorio nacional, sin embargo sólo se construyeron la mitad. En Madrid los grupos erigidos fueron García Noblejas, La Elipa y:

\section{Puerta Bonita (Usera)}

Arquitecto: Rafael Aburto.

Construcciones en altura con alto número de viviendas y densidad habitacional elevada. Se impone así el criterio del Ministerio de la Vivienda, y la

${ }_{44}$ Palabras de Arrese en la presentación del Plan. Citado en MOYA GOnZález: Op. cit., pág. 38. 


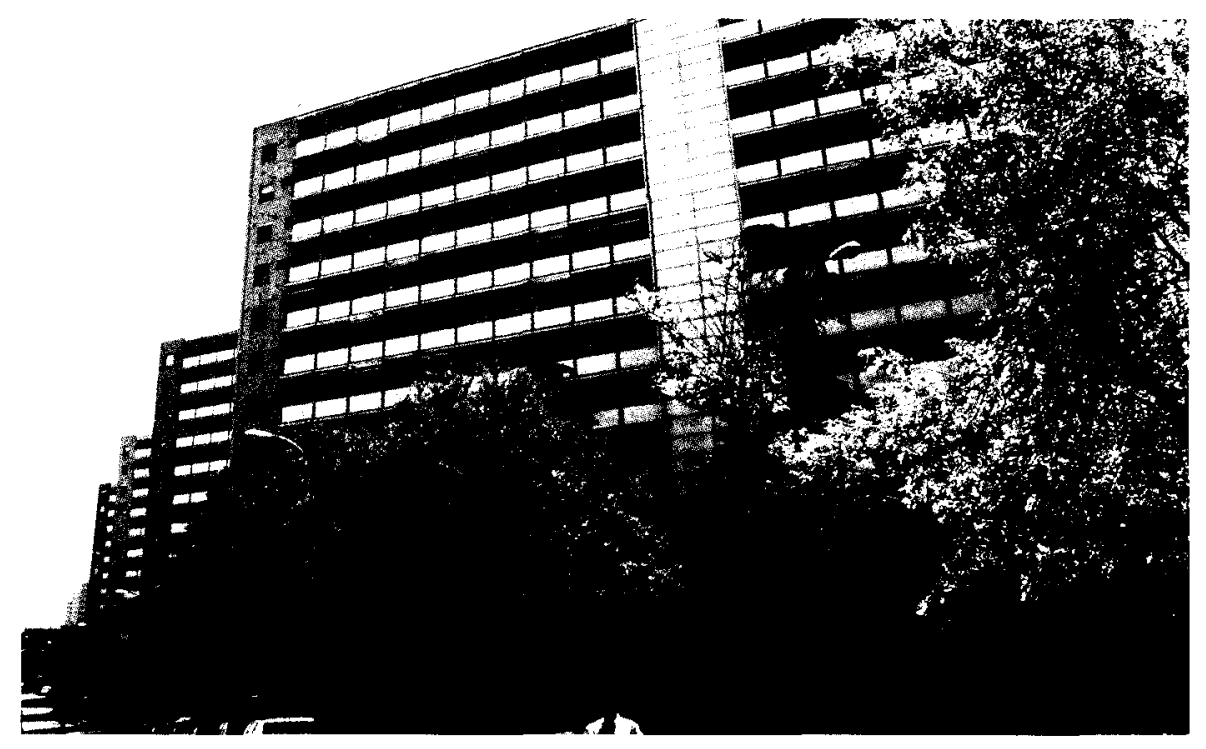

Puerta Bonita (Usera).

OSH se incorpora al nuevo estilo de ciudad, donde la alta densidad provocada por la construcción rentable copa los nuevos barrios. La actuación recuerda a las propuestas de Secundino Zuazo de vivienda en bloque de altura en su proyecto de prolongación del Paseo de la Castellana.

\section{EPILOGO}

Desde 1939 hasta 1957 se produjo una notable transformación de la vivienda social, tanto en su calificación legal, como en su desarrollo arquitectónico y urbano, y posiblemente también en su propia concepción política y social. La política de vivienda social del gobierno de Franco en estas décadas se vio sin duda afectada por la penuria de la dura posguerra; por la incapacidad económica, financiera e industrial del país; agravada por la nefasta política autárquica elegida por el Régimen; dividida por las propuestas de las diferentes familias políticas; empeorada por la masiva inmigración rural en las periferias urbanas, sobre todo en Madrid; pero también se debe reconocer que hasta mediados de los 50 , el Régimen franquista no trató el problema de la vivienda social como una cuestión de máxima urgencia y necesitada de todo el apoyo y capacidad del país. 
¿Imposibilidad económica? ¿Revanchismo político? Franco y su gobierno optaron por el camino de la autarquía económica, y la maquinaria represora de la Dictadura no fue nunca clemente con los derrotados de la Guerra Civil, habitantes en su mayoría de los barrios obreros del Madrid republicano. Hasta qué punto las decisiones en política social estaban más influidas por el aspecto político o el económico es difícil de delimitar. El punto de inflexión se produce al tomar el último vagón del desarrollo con los Planes de Estabilidad de 1959, a pesar del disgusto de buena parte del Régimen.

Respecto al aspecto arquitectónico de la vivienda social, hemos hecho mención del aspecto rural de la mayoría de las actuaciones de los años 40. Aunque el modelo de poblado permaneció hasta la década de los 50 , con los poblados de absorción y los dirigidos, la aportación que para entonces realizaban una joven generación de arquitectos, retomando en algún grado postulados racionalistas o simplemente novedosos. La raíz del cambio se encuentra en que se mira a los modelos de la arquitectura racionalista anterior a la guerra, mientras que por otro lado se comienza a observar la arquitectura exterior, gracias a algunas revistas arquitectónicas del momento, y en parte a la experiencia personal de los arquitectos que salen poco a poco al exterior (así es como los arquitectos de la OSH se deciden a retomar la solución en altura en 1954) en busca de sistemas constructivos que abaratasen los costos (camino iniciado por las famosas bóvedas tabicadas de Moya o Cabrero), alentando esta actitud diversos concursos, congresos y experiencias desde 1949.

Es importante también destacar el papel de la autoconstrucción (la "prestación personal»), promovida desde finales de los 40 por las constructoras benéficas dirigidas por arquitectos para obreros de la construcción, elemento que se terminó convirtiendo en uso legal y en piedra angular de la erección de los poblados dirigidos.

Los poblados de absorción y los poblados dirigidos se convirtieron desde entonces en espejo donde mirarse complaciente la arquitectura española. Su valor arquitectónico e histórico es indiscutible, pero el cometido que debían realizar nunca se cumplió. No sólo por la incapacidad de resolver un problema que con viviendas unifamiliares se convertia en caro e irrealizable, sino en el terreno urbanístico, como señala Sambricio, al quedar aislados de sus núcleos de referencia, "sin servicios y equipamientos colectivos sin las condiciones adecuadas para que en ellos naciera la vida urbana» ${ }^{45}$.

45 Sambricio: Op. cit. pág. 50. 
La entrada del capital privado en 1957 a través del Plan de Urgencia Social, y en 1961 con el Plan Nacional de la Vivienda (con la retirada de la joven arquitectura española que colaboró en los poblados), produjo un urbanismo y una construcción de viviendas que favorecieron la marginación y el deterioro social de los nuevos barrios durante las décadas de 1960 y 1970. La "cantidad", tan deseada y necesaria, ahogó por completo la arquitectura y el urbanismo que Madrid tantas veces (como Zuazo o Bidagor) diseñó en sus planos. 